Review Article

\title{
A Compressive Review on High- and Low-Temperature Performance of Asphalt Modified with Nanomodifier
}

\author{
Limin Li, ${ }^{1}$ Lingming Yang $\mathbb{D},{ }^{1}$ Yuliang Lin, ${ }^{2}$ and Xiancai Zhang ${ }^{1}$ \\ ${ }^{1}$ School of Civil and Environmental Engineering, Hunan University of Science and Engineering, Yongzhou 425199, China \\ ${ }^{2}$ School of Civil Engineering, Central South University, Changsha 410075, China \\ Correspondence should be addressed to Lingming Yang; 202031000194@smail.xtu.edu.cn
}

Received 19 February 2021; Revised 16 March 2021; Accepted 26 March 2021; Published 7 April 2021

Academic Editor: Ştefan Ţălu

Copyright $\odot 2021$ Limin Li et al. This is an open access article distributed under the Creative Commons Attribution License, which permits unrestricted use, distribution, and reproduction in any medium, provided the original work is properly cited.

At present, rutting and cracking have become serious issues in asphalt pavement, especially in the areas of summer heat and winter cold. Nanomodifier has been widely used in recent years due to its unique properties in improving the characteristics of asphalt binders. To make better use of nanomodifier to solve the problem of rutting and cracking of pavement, a compressive review on the high- and low-temperature performance of nanomodified asphalt is performed. The results indicate that for high- and low-temperature performance of asphalt binder, the effectiveness of nanomodification is found to be strictly influenced by the combination of original asphalt type, nanomodifier type, nanomodifier dosage, nanoparticle size, and preparation of nanomodified asphalt, and the high-temperature antirutting performance and low-temperature crack resistance of final blends are various with the combination. Chemical composition, microstructure, dispersion, and compatibility of final blends were the possible reason causing the difference. The rational selection of the combination can improve the high-temperature rutting resistance and the low-temperature cracking resistance of asphalt binder. So far, there is a lack of systematic investigation in this regard. Therefore, it is very necessary to study systematically the original asphalt, nanomodifier, nanomodifier dosage, nanoparticle size, and preparation of nanomodified asphalt effect on the high and low performance of nanomodified asphalt, especially in the modification mechanism in the future.

\section{Introduction}

With the constant increase of heavy axle loads, heavy traffic flow, and the traffic channelization of modern highway traffic, rutting and cracking have been regarded as serious issues confronting asphalt pavement, especially in the areas of summer heat and winter cold $[1,2]$. Therefore, it is necessary to research a new type of modified asphalt with excellent thermal stability and low-temperature cracking performance. Some published researches have proved that nanomodifier can play a significant role in enhancing the performance of asphalt binder and that it has shown the potential to solve the serious issues confronting asphalt pavement $[3,4]$. Nanomodified asphalt has become the research hotspots in recent years [5-7]. Many studies on the high- and low-temperature performance of nanomodified asphalt have been performed. Liu et al. [8] investigated the effect on microstructure and properties of the organic montmorillonite (OMMT) and OMMT/ethylene vinyl acetate (EVA)/asphalt composites and found that the OMMT/ EVA/asphalt composites were of good rutting resistance, superior anticracking, and high elasticity properties. The research of the characterization of viscoelastic behaviors of bitumen and bituminous mixture modified by nano- $\mathrm{TiO}_{2} /$ $\mathrm{CaCO}_{3}$ was performed by $\mathrm{Wu}$ et al. [9].The results showed that the incorporation of nano- $\mathrm{TiO}_{2} / \mathrm{CaCO}_{3}$ in bituminous mixture could significantly enhance the high-temperature antirutting and slightly improve the low-temperature anticracking as well. Amini et al. [10] analyzed the rutting performance, fatigue response, and rheological properties of nanoclay-modified asphalt rubber binder. They claimed that the addition of nanoclay led to an improving temperature susceptibility, rheological and physical properties of asphalt rubber binder, and that the nanoclay-modified asphalt 
rubber binder had high rutting resistance. Yusoff et al. $[11,12]$ found that the permanent deformation of the conventional asphaltic mixture with nano- $\mathrm{SiO}_{2}$ addition decreased. Shu et al. [13] studied the low-temperature performance of Carbon Nanotube- (CNT-) modified asphalt using the Bending Beam Remoter (BBR) test and found that the creep stiffness change rate $m$ of CNT-modified asphalt increased. In contrast, its creep stiffness decreased with the increase of the CNT content. Ghanoon et al. [14] investigated the effect of nanosilica modification on rutting resistance of asphalt binder and found that addition of nano- $\mathrm{SiO}_{2}$ significantly improved bitumen resistance to rutting, and this improvement had a rising trend with the increase in percentage up to $6 \%$. The effects of nano/styrene-butadiene rubber (SBR) polymer on rutting performance of binder and asphalt mixture were studied by Mahmoud et al. [15]. The results indicated that nanoclay had considerably positive impact on rutting and elastic deformation of neat and SBRmodified asphalt binder and mixture. Arabani and Faramarzi [16] investigated mechanical properties of CNTmodified asphalt mixtures and found that the permanent deformations of CNT-modified asphalt mixtures reduced. The high-temperature performance of nano- $\mathrm{ZnO}$ was investigated by Arabani et al. [17] through laboratory experiments and found that the addition of nano- $\mathrm{ZnO}$ could decrease the permanent deformation of asphalt binder. Wang et al. [18] reported that the incorporation of hydrophobic nanosilica could enhance the viscoelasticity and high-temperature stability of asphalt mixture. Bhat and Mir [19] found that the addition of nano- $-\mathrm{Al}_{2} \mathrm{O}_{3}$ had a positive effect on the rutting and fatigue performance of styrenebutadiene-styrene- (SBS-) modified asphalt binders. Ameli et al. [20] evaluated the effect of nano- $\mathrm{TiO}_{2}$ on the performance behavior of bitumen and stone matrix asphalt specimens and claimed that the utilization of nano- $\mathrm{TiO}_{2}$ caused the binder strain to decrease and led the rutting behavior of bitumen to increase. Simultaneously, rutting resistance increased by the addition of more percentages of nano- $\mathrm{TiO}_{2}$. Anwar et al. [21] found that addition of multiwalled carbon nanotubes (MWCNTs) by $1.5(\% \mathrm{w} / \mathrm{w})$ of asphalt binder reduced penetration grade by $14.4 \%$ with an increase of $10.2 \%$ and $40 \%$ in softening point and ductility, respectively.

Although a great deal of researches on high- and low-temperature performance of nanomodified asphalt have been conducted, they mainly focused on high- and low-temperature performance of certain nanomodifier on certain asphalt binders. There is a lack of systematic investigations on the high- and low-temperature performance of nanomodified asphalt. In fact, the high and low temperature of nanomodified asphalt strongly depends upon the type of asphalt binder and nanomodifier, nanomodifier content, nanoparticle size, and preparation of nanomodified asphalt [22]. Therefore, to make better use of nanomodifier to control rutting and cracking of asphalt pavement, it is necessary to systematically investigate the high- and low-temperature performance of asphalt binder modified with nanomaterial based on the previous researches.

\section{High- and Low-Temperature Performance of Nanomodified Asphalt for Different Original Asphalt}

Li [23] studied the high- and low-temperature performance of nano- $\mathrm{ZnO}$-modified asphalt for three kinds of original asphalt, and the results indicated that for Caltex $\mathrm{AH}-70$ asphalt, Zhonghai AH-70 asphalt, and Zhonghai AH-90 asphalt, addition of nano- $\mathrm{ZnO}$ by $7(\% \mathrm{w} / \mathrm{w})$ of bituminous binder, respectively, increased softening point by $3.1 \%$, $4.4 \%$, and $3.5 \%$ with an increase of $114.8 \%, 102.0 \%$, and $69.5 \%$ in ductility, respectively. Sun et al. [24] investigated the high- and low-temperature performance of nano-I modified asphalt for AH-70 and 5\% SBS-modified asphalt. The results showed that for AH-70 original asphalt, addition of nano-I by $5(\% \mathrm{w} / \mathrm{w})$ of bituminous binder increased softening point by $20.9 \%$ with a reduction of $56.9 \%$ in ductility, respectively. For 5\% SBS-modified asphalt, addition of nano-I by $5(\% \mathrm{w} / \mathrm{w})$ of bituminous binder increased softening point by $5.7 \%$ with an increase of $5.2 \%$ in ductility, respectively. Moreover, at $64^{\circ} \mathrm{C}$, compared with the original asphalt, the rutting factor of $\mathrm{AH}-70$ asphalt modified with nano-I and SBS asphalt modified with nanoI was increased by $194.0 \%$ and $23.9 \%$, respectively. At $-12^{\circ} \mathrm{C}$, compared with $\mathrm{AH}-70$ original asphalt, the creep stiffness of its nano-I-modified asphalt was decreased by $30.4 \%$, while in comparison with $5 \%$ SBS-modified asphalt, the creep stiffness of its nano-I-modified asphalt was increased by $20 \%$. The high- and low-temperature performance of nano-ZnO-modified asphalt for three kinds of original asphalt was investigated by Zhang et al. [25]. The results indicated that for matrix asphalt, 3\% SBS-modified asphalt and $4 \%$ SBS-modified asphalt, the increase amplitudes of the rutting factors of nano- $\mathrm{ZnO}$ modified asphalt were the greatest at $64^{\circ} \mathrm{C}$, which were $58.3 \%, 35.5 \%$, and $8.5 \%$, respectively, while at $-12^{\circ} \mathrm{C}$, the increase amplitudes of the creep stiffness of their nano-ZnO-modified asphalt were $4.8 \%, 3.9 \%$, and $3.0 \%$, respectively. Ye and Chen [26] reported the physical properties of based on Karamay AH-70 original asphalt and SBS-modified asphalt containing various amounts of nano- $\mathrm{SiO}_{2}$. The results showed that for Karamay AH-70 asphalt and 3\% SBSmodified asphalt, addition of nano- $\mathrm{SiO}_{2}$ by $0.5(\% \mathrm{w} / \mathrm{w})$ of bituminous binder, respectively, increased softening point by $8.9 \%, 4.1 \%$ with a reduction of $30.2 \%, 49.3 \%$ in ductility, respectively. Their findings were shown in Figures 1-4. Furthermore, Xiao and Amirkhanian [27] studied the hightemperature properties of five kinds of original asphalt modified with carbon nanoparticles and demonstrated that the original asphalt played a key role in determining the high-temperature rheological properties of nanomodified asphalt. Zhang et al. [28] researched the high- and low-temperature performance of multidimensional nanomaterials ( $2 \% \mathrm{ZnO}$ and $1 \%$ vermiculite) modified asphalt of the South Korea AH-70 (SK-70) asphalt, Alfa-70 asphalt, SBS-modified asphalt, and SBR-modified asphalt, and the results indicated that for SK-70 asphalt, Alfa-70 asphalt, SBS-modified asphalt, and SBR-modified asphalt, in 


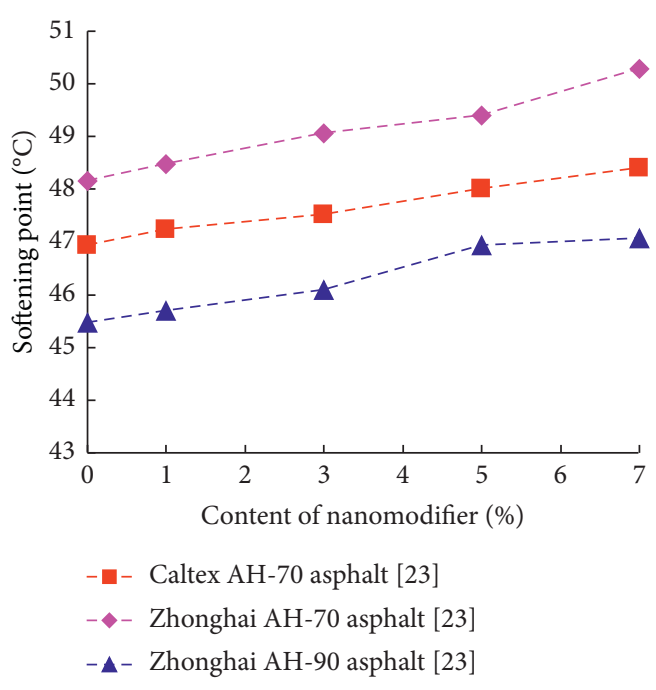

(a)

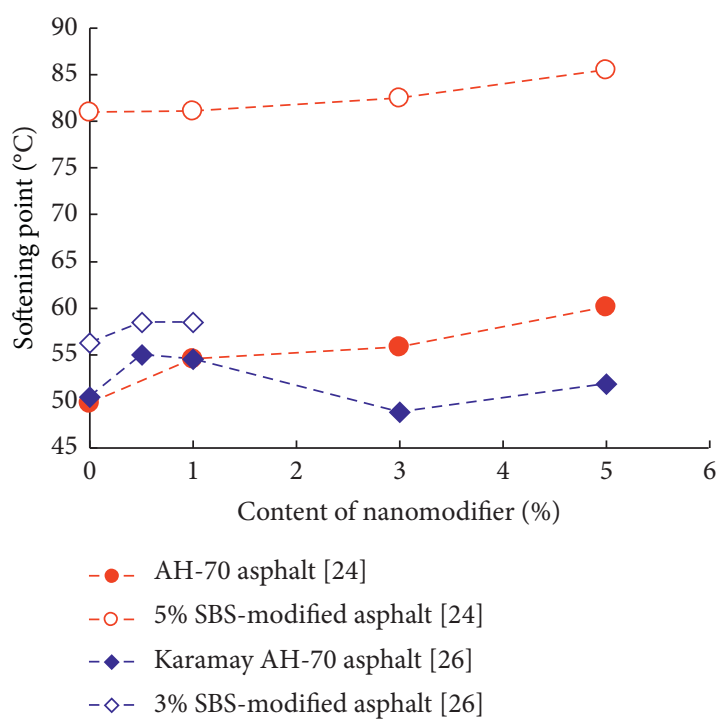

(b)

Figure 1: Softening point of different asphalt.

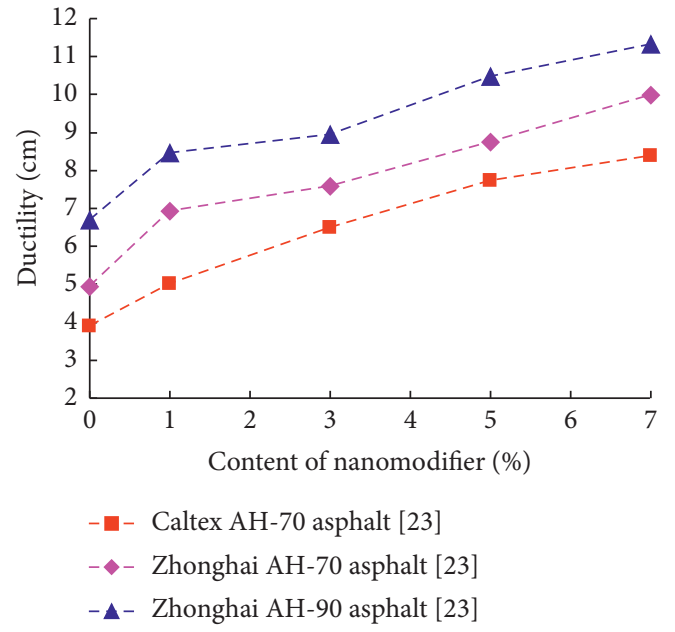

(a)

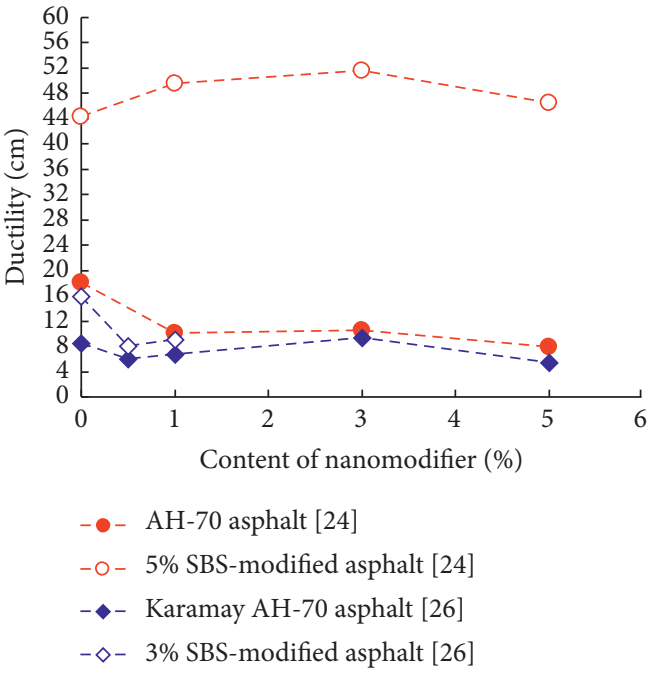

(b)

Figure 2: Ductility of different asphalt at $5^{\circ} \mathrm{C}$.

comparison with original asphalt, the creep stiffness of their nanomodified asphalt was increased by $34.4 \%$ $, 21.3 \%, 15.9 \%$, and $16.3 \%$, respectively, and the higher the rutting factor of original asphalt was, the higher the rutting factor of its nanomodified asphalt was.

In fact, the softening point can affect the stiffness of bituminous binder. The bigger the softening point of asphalt is, the stronger its high temperature rutting resistance is [15]. Ductility can affect the flexibility of asphalt, and it can evaluate the tensile deformation ability of the bituminous binder. The ductility of asphalt is smaller, and its crack resistance is better [29]. The rutting factor and the creep stiffness can evaluate the high-temperature rutting resistance and the low-temperature cracking resistance of asphalt binder, respectively. A larger value of rutting factor corresponds to a better high-temperature rutting resistance of bituminous binder [27], and a smaller creep stiffness value is expected to lead to smaller tensile stresses in the bituminous binder and less chance for low-temperature cracking [30]. As shown in Figure 1 through Figure 4, the high- and low-temperature properties of nanomodified asphalt were obviously affected by its original asphalt type. The hightemperature properties of different original asphalt modified with the same nanomodifier can all be improved. The better the high-temperature property of original asphalt is, the stronger the high-temperature rutting resistance of its nanomodified asphalt becomes. Meanwhile, the low-temperature properties of different original asphalt modified with the same nanomodifier may be increased or decreased. Simultaneously, the better the low-temperature property of 


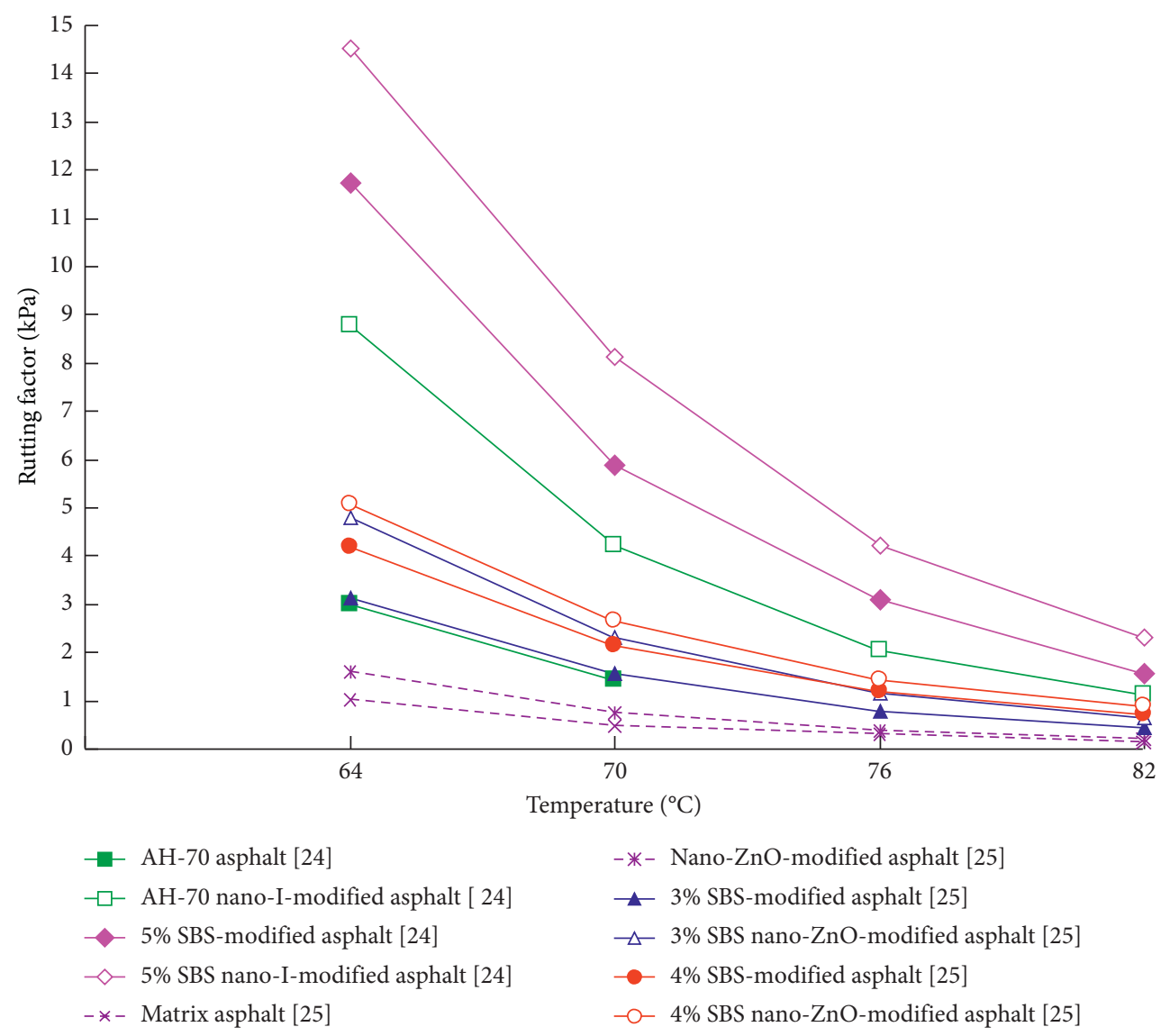

FIgURE 3: Rutting factor of different asphalt.

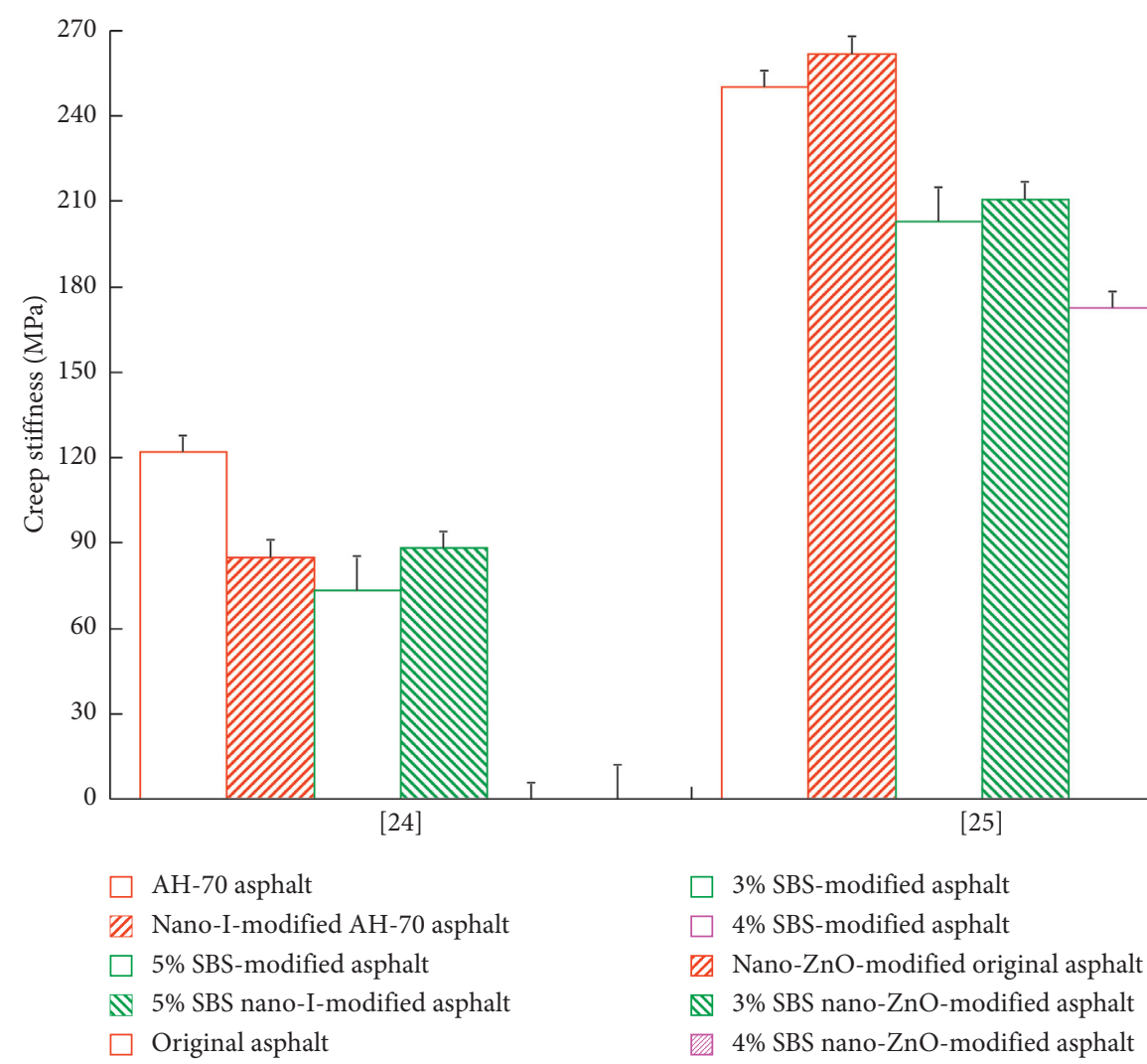

Figure 4: Creep stiffness of different asphalt at $-12^{\circ} \mathrm{C}$. 
original asphalt is, the stronger the low-temperature crack resistance of its nanomodified asphalt becomes. Different chemical composition of the original asphalt was the possible reason causing the difference, and its physicochemical nature seems to play a role of primary importance in the definition of the high- and low-temperature properties of final blends. Hence, the rational selection of original asphalt can improve the high rutting resistance and lowtemperature cracking resistance of nanomodified asphalt. Also, it is feasible to select the original asphalt according to its high- and low-temperature property. So far, limited investigation on the high and low performance of nanomodified asphalt for different original asphalt has been reported. Therefore, to make better use of nanomodifier to control rutting and cracking of asphalt pavement, it is very necessary to study systematically the original asphalt effect on the high and low performance of nanomodified asphalt, especially in the modification mechanism in this regard.

\section{High- and Low-Temperature Performance of Asphalt Modified with Different Nanomodifier}

Ye and Chen [26] analyzed the high- and low-temperature performance of nano- $\mathrm{TiO}_{2}$-modified asphalt and nano$\mathrm{SiO}_{2}$-modified asphalt and found that for Karamay AH-70 asphalt and $5 \%$ nano- $\mathrm{SiO}_{2}$ dosage, with the addition of nano- $\mathrm{TiO}_{2}$, the ductility at $5^{\circ} \mathrm{C}$ showed a $9.4 \%$ increase, and with the addition of nano- $\mathrm{SiO}_{2}$, the ductility showed a $6.9 \%$ decrease. The addition of nano- $\mathrm{SiO}_{2}$ had a positive effect on the low-temperature performance of bituminous binder, while the addition of nano- $\mathrm{TiO}_{2}$ had a better effect on the high-temperature performance of bituminous binder than that of nano- $\mathrm{SiO}_{2}$. Zhang et al. [31] declared that, at the same concentrations of $5 \%$, the addition of five kinds of nanomodifier could enhance the softening point of SK-70 original asphalt, and the order of improvement effect of nanomodifier on softening point was nano$\mathrm{Fe}_{3} \mathrm{O}_{4}<$ nano-montmorillonite (nano-MMT) $<$ nano$\mathrm{CaCO}_{3}<$ nano- $\mathrm{ZnO}<$ nano- $\mathrm{TiO}_{2}$. The softening point of nano- $\mathrm{TiO}_{2}$-modified asphalt increased by $23.9 \%$ than that of SK-70 original asphalt. Moreover, addition of nano$\mathrm{ZnO}$ and nano- $\mathrm{TiO}_{2}$ increased the ductility at $5^{\circ} \mathrm{C}$ of SK-70 original asphalt by $14.7 \%$ and $4.4 \%$, respectively. However, the addition of nano- $\mathrm{CaCO}_{3}$, nano- $\mathrm{Fe}_{3} \mathrm{O}_{4}$, and nanoMMT decreased the ductility of SK-70 original asphalt by $9.6 \%, 9.6 \%$, and $26.5 \%$, respectively, and they had negative effects on the ductility of SK-70 bituminous binder. Moreover, they claimed that the physical and chemical reactions in nanoparticles/polymer modified asphalt might significantly alter the structure of base asphalt and result in excellent mechanics and mechanical properties of modified asphalt. Tsantilis et al. [32] investigated the lowtemperature performance of nanomodified asphalt and claimed that the effectiveness of nanomodification was found to be strictly influenced by the additive type. For example, at $-12^{\circ} \mathrm{C}$, for a $70 / 100$ penetration grade bitumen, labelled B1, and carbon nanotubes (CNT) and two kinds of nanoclay (NCA and NCB), addition of nanoCNT, nano-NCA, and nano-NCB decreased the creep stiffness of original asphalt B1 by $6.3 \%, 15.2 \%$, and $2.2 \%$, respectively. Shahabadi et al. [33] studied the high- and low-temperature performance of nanomodified asphalt, using the $60 / 70$ penetration grade bituminous supplied by Pasargad Oil Co., Tehran, Iran (Pasargadae AH-70 asphalt) and the modifier of organically modified bentonite (OBT) and bentonite clay (BT) and found that the nano-OBT-modified asphalt had better high- and lowtemperature properties than those of nano-BT-modified asphalt. Yao et al. [34] evaluated the low-temperature properties of the nonmodified nanoclay- (NMN-) modified asphalt and the modified polymer modified nanoclay(PMN-) modified asphalt by BBR test, and the results showed that the creep stiffness values of PMN-modified asphalt were bigger than those of NMN-modified asphalt under the same conditions. Zhang et al. [35] claimed that the nanoparticles of nano- $\mathrm{ZnO}$, nano- $\mathrm{TiO}_{2}$, and nano- $\mathrm{SiO}_{2}$ had different influence on the softening point of original asphalt, and the relationship of the softening points of their modified asphalt was nano- $\mathrm{SiO}_{2}<$ nano$\mathrm{TiO}_{2}<$ nano-ZnO. In comparison with nano- $\mathrm{SiO}_{2}$ and nano- $\mathrm{TiO}_{2}$, the softening point increment of nano- $\mathrm{ZnO}$ modified asphalt was maximum, which was $2.1^{\circ} \mathrm{C}$. Moreover, the surface modified inorganic nanoparticles could enhance the ductility of bitumen, and the relationship of the ductility of their modified asphalt was nano- $\mathrm{TiO}_{2}<$ nano- $\mathrm{SiO}_{2}<$ nano- $\mathrm{ZnO}$. Jahromi and Khodaii [36] researched the high- and low-temperature properties of a 60/70 penetration grade bitumen (AC-10), respectively, modified by Nanofil-15 and nanocloisite$15 \mathrm{~A}$. The results indicated that for AC-10 original asphalt, addition of Nanofil-15 by $7(\% \mathrm{w} / \mathrm{w})$ of bituminous binder, respectively, increased softening point by $3.1 \%$ and $13.1 \%$ with a decrease of $20.0 \%$ and $25.8 \%$ in ductility, respectively. Wang [37] reported that at the same dosage of $3 \%$, the softening point of nano organophilic montmorillonite- (nano-OMMT-) modified asphalt and nano sodium montmorillonite- (nano-Na-MMT-) modified asphalt was increased by $7.4^{\circ} \mathrm{C}$ and $9.5^{\circ} \mathrm{C}$, respectively, than that of SBS-modified asphalt, and under the same conditions, the rutting factor of nano-OMMT SBS-modified bitumen was bigger than that of nano-Na-MMT SBS-modified bitumen. Furthermore, the ductility of nano-OMMT- modified asphalt and nano-Na-MMT-modified asphalt was smaller than that of SBS-modified bitumen, and when the dosage of nanomodifier is less than 1.5, the ductility of nano-OMMT is bigger than that of nano-Na-MMT. Saltan et al. [38] found that for the original asphalt of PG 64-22 performance grade, addition of carbon nanotubes doped with $50 \% \mathrm{Nano}^{-\mathrm{SiO}_{2}}\left(\mathrm{SiO}_{2}\right.$-doped $\left.\mathrm{CNT}\right)$ and multiwalled carbon nanotube (MWCNT) by $5(\% \mathrm{w} / \mathrm{w})$ of bituminous binder, respectively, increased softening point by $7.31 \%$ and $0.8 \%$ with an increase of $12.2 \%$ and $4.2 \%$ in rutting performance, respectively, and their creep stiffness of $-12^{\circ} \mathrm{C}$ was increased by $12.2 \%$ and $4.22 \%$, respectively. Therefore, the high temperature of nano- $\mathrm{SiO}_{2}$-doped CNT-modified asphalt is better than that of MWCNT- 
modified asphalt, while its low temperature is worse than that of MWCNT-modified asphalt. You et al. [39] declared that nanoclay A modified asphalt had better lowtemperature cracking resistance and high-temperature rutting resistance than nanoclay B modified asphalt based upon the direct tension and dynamic shear modulus test. $\mathrm{Yu}$ et al. [40] claimed that for Taizhou AH-70 (TZ-70) original asphalt, the high-temperature rutting resistance of nano-OMMT-modified asphalt was better than that of nano-MMT-modified asphalt. Guo and Liu [41] investigated the high and low properties of the original asphalt of organic expanded vermiculite (OEVMT) modified by nano- $\mathrm{SiO}_{2}$, nano- $\mathrm{TiO}_{2}$, and nano- $\mathrm{ZnO}$ and found that high-temperature rutting resistance of nanomodified asphalt was better than that of the original asphalt, and its order was nano- $\mathrm{ZnO}>$ nano- $\mathrm{SiO}_{2}>$ nano$\mathrm{TiO}_{2}$, while the low-temperature cracking resistance of nanomodified asphalt was worse than that of the original asphalt, and its order was nano- $\mathrm{ZnO}>$ nano- $\mathrm{SiO}_{2}>$ nano$\mathrm{TiO}_{2}$. The high-temperature performance of nano- $\mathrm{ZnO}$ modified asphalt was the best, while its low-temperature performance was the worst. Typical findings of high- and low-temperature properties of asphalt modified with different nanomodifier are shown in Figures 5-8.

As shown in Figure 5 through Figure 8, nanomodifier type significantly affects the high- and low-temperature performance of its modified asphalt, and for the same original asphalt, the addition of nanomodifier can increase the high-temperature properties of its nanomodified asphalt, and the rutting resistance increment depends on the type of nanomodifier, while the addition of nanomodifier may have a negative effect on the low-temperature performance. Moreover, the increase or decrease of the low-temperature cracking resistance of its nanomodified asphalt depends on the type of nanomodifier too. Different chemical composition of nanomodifier and the microstructure of final blends are the possible reason causing the difference. Hence, the rational selection of nanomodifier can improve the highand low-temperature cracking resistance of nanomodified asphalt. So far, limited investigation on the high and low performance of nanomodified asphalt for different nanomodifier has been reported. Therefore, to make better use of nanomodifier to control rutting and cracking of asphalt pavement, it is very necessary to study systematically the nanomodifier effect on the high and low performance of nanomodified asphalt, especially in modification mechanism in this regard.

\section{High- and Low-Temperature Performance of Nanomodified Asphalt with Different Content}

Iskender [42] reported that for nanoclay modified asphalt mixtures, estimating reliable nanoclay content was very important in view of rutting evaluation, and nearly $50 \%$ lower permanent deformation could be calculated with selected nanoclay concentrations. Golestani et al. [43] found that for the Linear SBS-Nanocomposite-
(LSN-) modified asphalts and Branch SBS-Nanocomposite- (BSN-) modified asphalts, at SBS/ OMMT $=100 / 25$ ratio, the complex shear modulus curves had the maximum increment, and phase angle curves indicated minimum values. Hence, the ratio could indicate the maximum resistance in rutting values and also could be selected as an optimum ratio. Abdullah et al. and other researchers [44-48] reported that, for nanomodified asphalt, as the nanomodifier content increased, the high-temperature rutting resistance increased. Meanwhile, the low-temperature cracking resistance decreases depending on nanomodifier content. Han et al. [49] found that the softening point of nano-OMMT SBS modified asphalt increased with the increase of nano-OMMT content. When the nano-OMMT dosage was bigger than $3 \%$, its increase rate slowed down. With the increase of nano-OMMT content, the ductility at $5^{\circ} \mathrm{C}$ tended to increase at first and then tended to decrease. Moreover, the binder with 3\% nano-OMMT exhibited the highest ductility. Based on the high- and low-temperature performance, its optimal dosage was 3\%. For nano- $\mathrm{ZnO} \mathrm{AH}-70$-modified asphalt, Zhang [50] obtained a similar conclusion. Ashish and Singh [51] declared that nano-CNT content up to $1.5 \%$ might be helpful against resisting the rutting failure. However, the addition of a higher dosage of nano-CNT (2.25\% and above) might not be advisable as per Superpave rutting parameter criteria due to its poor dispersion at higher nano-CNT content. Ashish et al. [52] claimed that for $6 \%$ organomodified nanoclay (CL-30B) binder, compared to $2 \%$ and $4 \%$ modification levels, an obvious increase in rutting factor was seen, and transformation of CL-30B structure from intercalated to exfoliated was the possible reason causing the difference. Liu [53] investigated the nano-OMMT content effect on the high and low temperature of 3\% SBS nano-OMMTmodified asphalt and found that as nano-OMMT content increased, its rutting factor obviously increased with the decrease of creep stiffness, respectively. Therefore, nanoOMMT content increase could effectively improve highand low-temperature performance of 3\% SBS nanoOMMT-modified asphalt. Fu [54] studied the high and low temperature of nano-OMMT modified AH-90 asphalt. It was found that when nano-OMMT content increased from $0 \%$ to $3 \%$, there was an increase in high-temperature properties. Moreover, there was an increase in low-temperature properties, when nanoOMMT content increased from $0 \%$ to $5 \%$. Furthermore, in comparison with the base asphalt after aging, the low-temperature crack performance of nano-OMMT-modified asphalt after aging was better with nano-OMMT content increasing. Shafabakhsh et al. [55] revealed that adding of nano- $\mathrm{TiO}_{2}(1 \%, 3 \%, 5 \%$, and $7 \%$ of the weight of the original asphalt) significantly increased the softening point of asphalt binder with the increase of the ductility of nano- $\mathrm{TiO}_{2}$-modified asphalt compared to original bitumen. As a result, as modifier of bitumen, the optimal content of nano- $\mathrm{TiO}_{2}$ was $5 \%$. $\mathrm{Zhu}$ et al. [56] observed that SBR-modified asphalt modified 


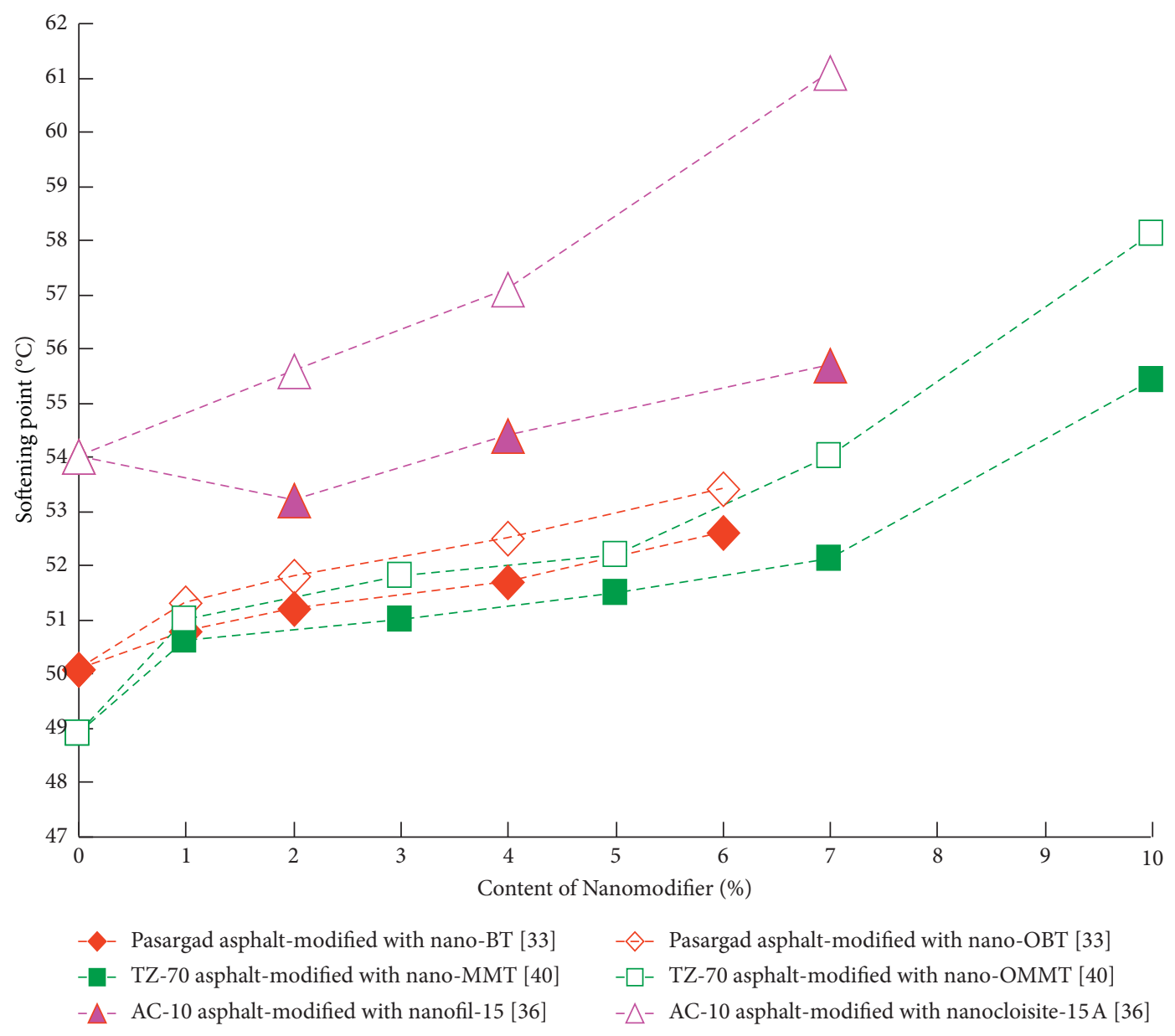

Figure 5: Softening point of nanomodified asphalt.

by multidimensional nanomaterials ( $1 \%$ OEVMT $+1 \%$ or $2 \%$ or $3 \%$ nano- $\mathrm{ZnO}$ ), $2 \%$ nano- $\mathrm{ZnO}$, and $2 \%$ OEVMT presented the higher rutting factor value than unmodified SBR-modified asphalt. Shu et al. [13] detected that multiwalled carbon nanotubes (MWCNTs) had a positive effect on the high- and low-temperature performance of the SBS-modified asphalt, and its optimum content was $1 \%$. Amin et al. [57] carried out laboratory evaluation aiming at investigating the effect on the rheological properties of asphalt with multiwalled carbon nanotubes and found that when the pristine multiwalled carbon nanotubes (P-MWCNTs) content was up to $3 \%$ by the weight, with the increase of $\mathrm{P}-\mathrm{MWCNTs}$, the rutting resistance increased, and the low-temperature cracking resistance decreased. Sun [58] claimed that nano-SiC content evidently affected the high- and low-temperature performance of its modified asphalt, and its optimal content was $6 \%$, based on the high- and low-temperature properties. Similarly, Du [59] studied the effect of nano-OEVMT content on its modified asphalt and found that nano-OEVMT content obviously affected the high- and low-temperature performance of its modified asphalt, and its optimal content was $4 \%$. Chen et al. [60] found that the addition of nano- $\mathrm{ZnO}$ varied as $1 \%, 4 \%$, and $7 \%$ by the weight of original binder could effectively improve the high- and low-temperature performance of its modified asphalt, and its optimal content was $4 \%$. Cao et al. [61, 62] reported that the high-temperature rutting resistance of nano- $\mathrm{SiO}_{2}$-modified could be improved with the increase of nano- $\mathrm{SiO}_{2}$ content and that a small amount of nano- $\mathrm{SiO}_{2}$ was helpful to improve the low-temperature cracking resistance; however, over seven percent of nano- $\mathrm{SiO}_{2}$ would damage its low-temperature cracking resistance. Therefore, the recommended dosage of nano- $\mathrm{SiO}_{2}$ is not more than $7 \%$. Typical findings are given in Figures 9-12 in this regard.

As shown in Figure 9 through Figure 12, the effectiveness of nanomodification is strictly influenced by the additive dosage, and nanomodifier dosage plays a role of significant importance in the definition of the high- and low-temperature performance of final blends As nanomodifier content increases, the high-temperature property of its modified asphalt can be improved, while its low-temperature property may be decreased at first. The different microstructure and composition of the asphalt binder is the possible reason causing the difference. Therefore, the rational selection of nanomodifier dosage is very important for the high and low temperature properties of nanomodified asphalt. To make better use of nanomodifier to control rutting and cracking of 

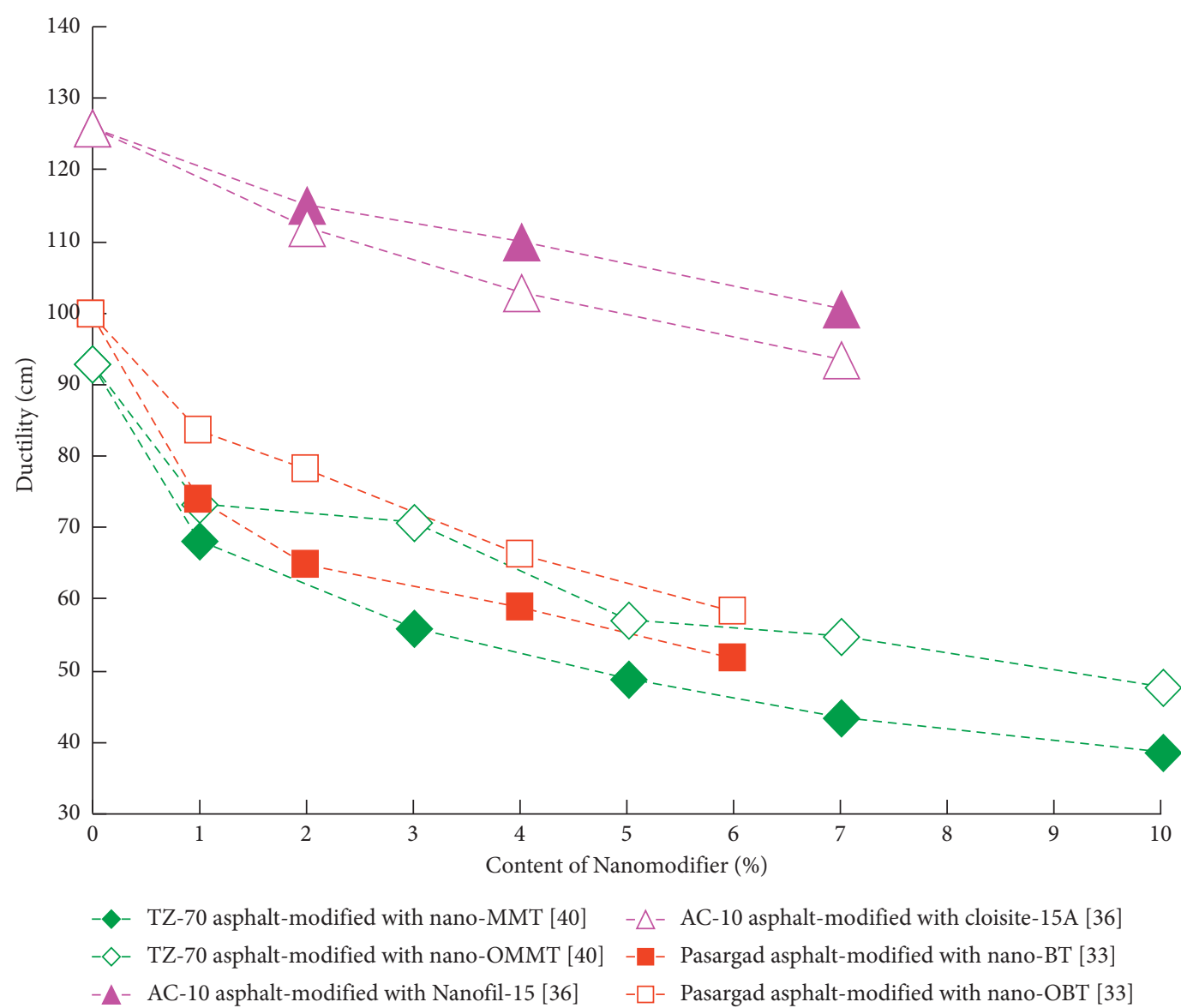

FIgURE 6: Ductility of nanomodified asphalt.

asphalt pavement, it is very necessary to study systematically the nanomodifier content effect on the high and low performance of nanomodified asphalt, especially in the modification mechanism in this regard.

\section{High- and Low-Temperature Performance of Nanomodified Asphalt with Different Nanoparticle Size}

Sun [58] found that nano-SiC particle size had a significant impact on high- and low-temperature properties, and its optimum particle size was $100 \mu \mathrm{m}$, based on its high- and low-temperature performance. Zhang et al. [25] reported that nano- $\mathrm{ZnO}$ particle size played an important role in determining its high- and low-temperature properties, and based on high- and low-temperature performance, its optimum particle size was $80 \mu \mathrm{m}$. Similarly, the same results were obtained by Li et al. [63]. Typical findings are given in Figures 13-16 in this regard (nanoparticle of $0 \mu \mathrm{m}$ diameter is equal to without nanoparticles in Figures 14 and 16).

As shown in Figures 13 through 16, the effectiveness of nanomodification is strictly influenced by the nanoparticle size, which has an important effect on the high- and low-temperature performance of asphalt binder, and that the particle size of nanomodifier cannot be too big or too small. Moreover, it is interesting that, under the same conditions, as the nanoparticle size increased, its high- and low-temperature properties sometimes increased and sometimes decreased. Different dispersion, compatibility, and microstructure of final blends are the possible reason causing the difference. So far, there are few studies on the effect of the nanoparticle size on the high- and low-temperature performance of asphalt binder. Therefore, this aspect should be further studied in the future.

\section{High- and Low-Temperature Performance of Nanomodified Asphalt for Different Preparation}

Preparation and properties of nanomaterials have been studied by some researchers. Alexandr et al. [64] investigated field emission behavior from the surface of a tip that was prepared from polymer graphite nanocomposites subjected to electrochemical etching. Kaspar et al. [65] found that the introduction of carbon had an effect on the electric properties of polyvinylidene fluoride. Talu [66] studied several aspects of topographic characterization of nanometric engineering surfaces, based on the application of the fractal/ multiracial theory. Sobola et al. [67] claimed that properly employed electrochemical etching with a bubble membrane creates sharp and smooth graphite tips, which can be given enough graphite content, used as probes in several 


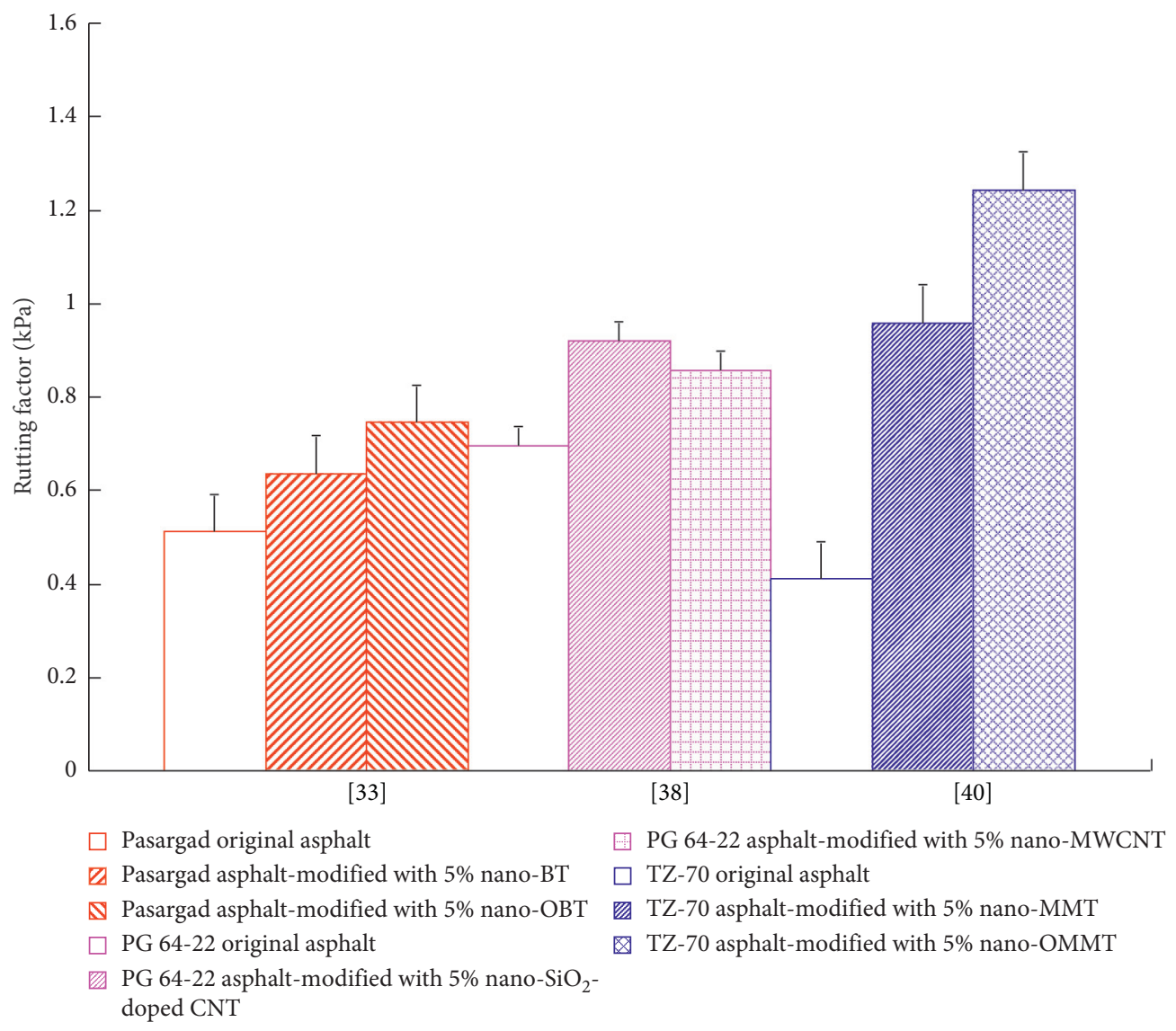

Figure 7: Rutting factor of nanomodified asphalt at $70^{\circ} \mathrm{C}$.

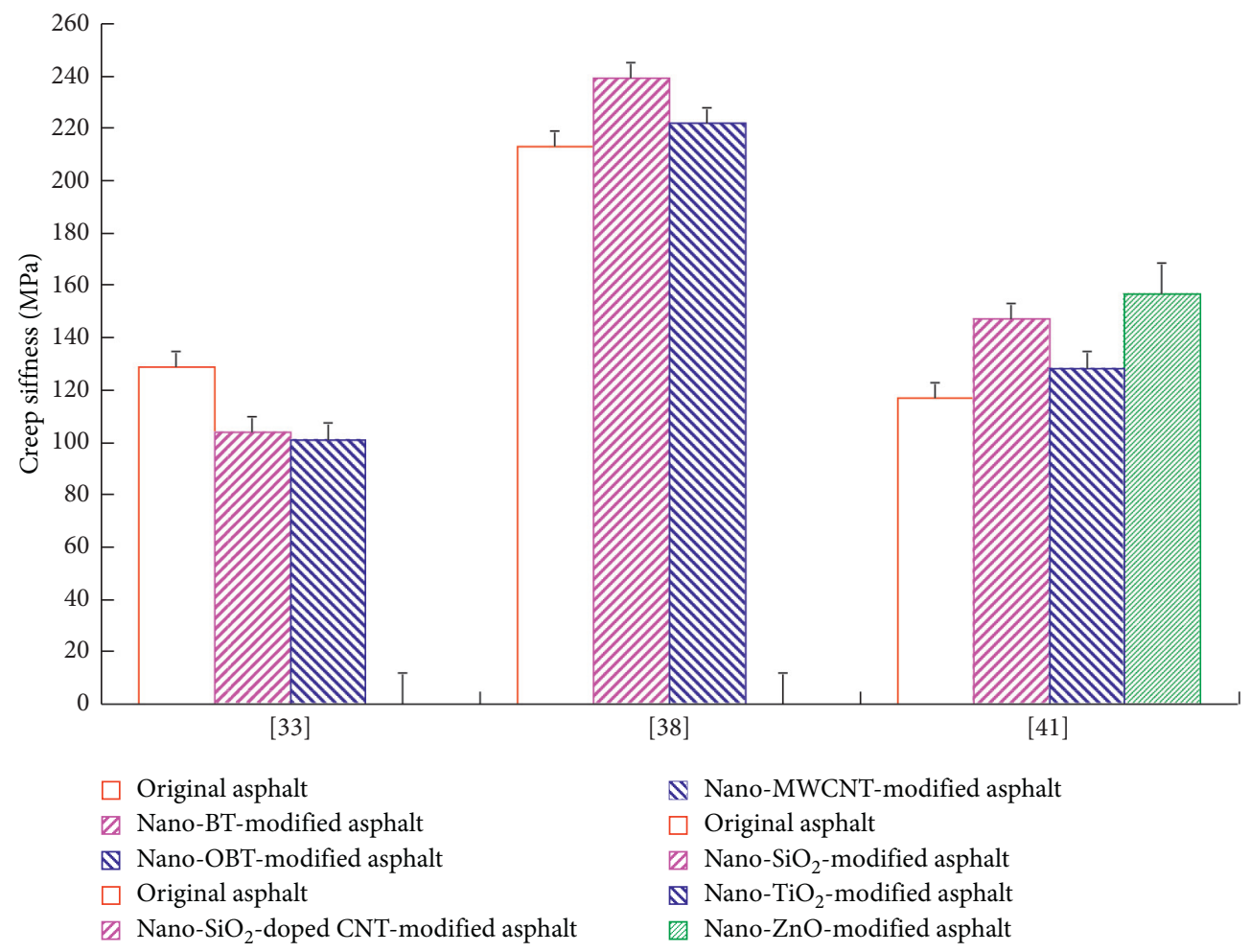

Figure 8: Creep stiffness of nanomodified asphalt at $-12^{\circ} \mathrm{C}$. 


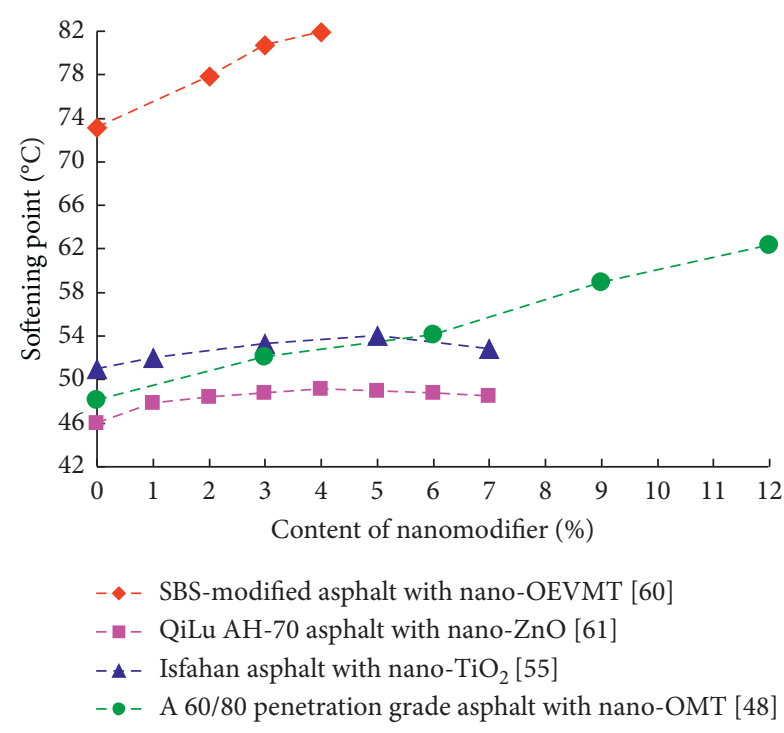

Figure 9: Softening point and nanomodifier content.

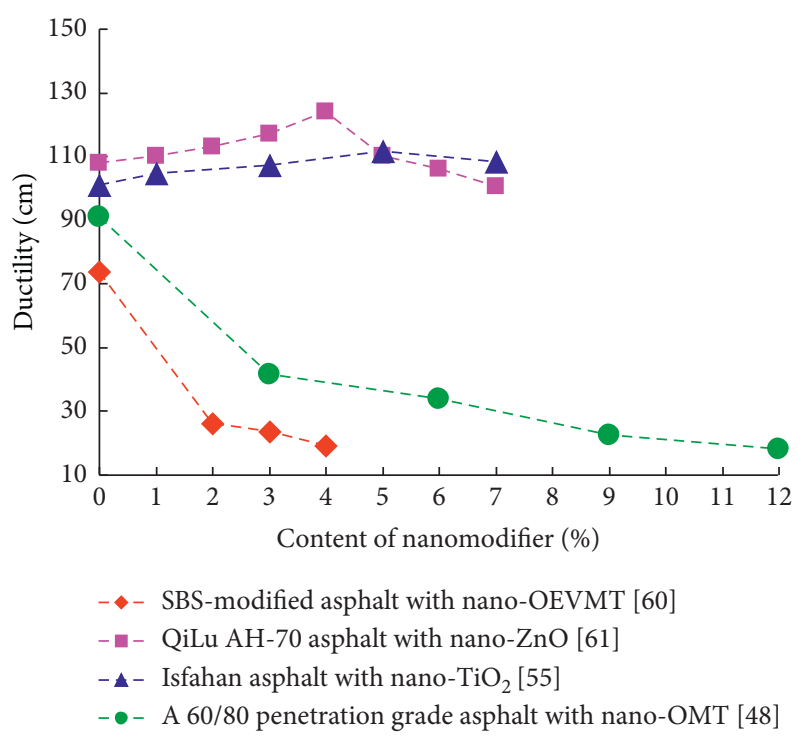

FIgURE 10: Ductility and nanomodifier content.

measurement techniques. To improve the compatibility of nanomodifier and asphalt binder, the high-speed shear method has been widely adopted by various researchers [68]. The mixing duration, mixing temperature, and rotational speed are the main effect factors for nanomaterial dispersion in asphalt binder using this approach. Typical preparation parameters adopted by researchers are given in Table 1, while the preparation parameter effect on the high and low temperature of nanomodified asphalt was not studied by them. $\mathrm{Li}$ [23] studied the mixing temperature and duration effect on the high- and low-temperature properties of SBS

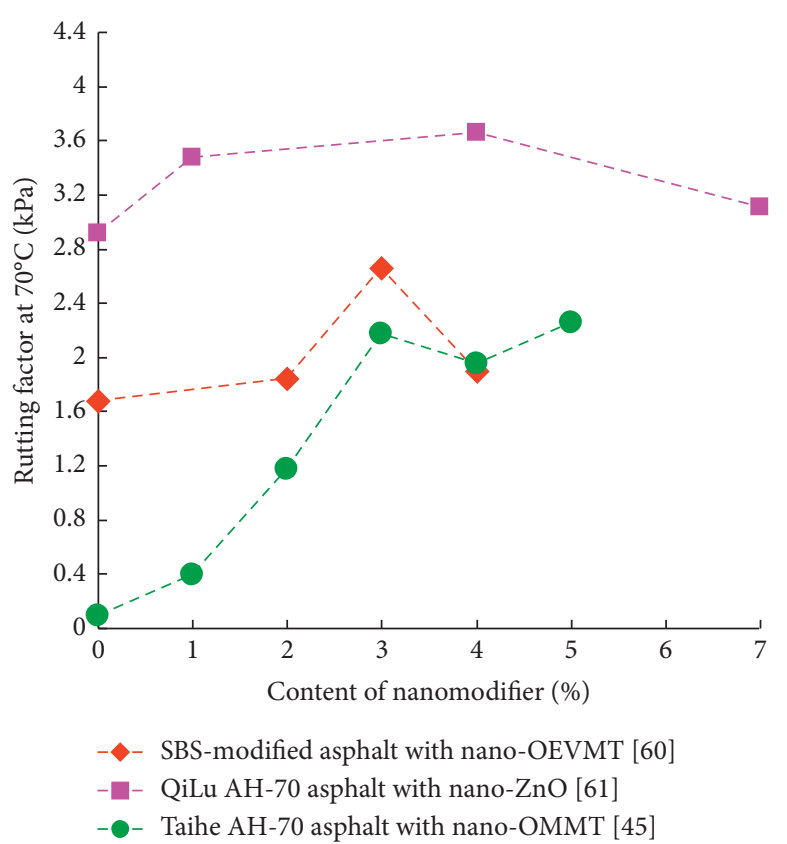

FIGURE 11: Rutting factor and nanomodifier content.

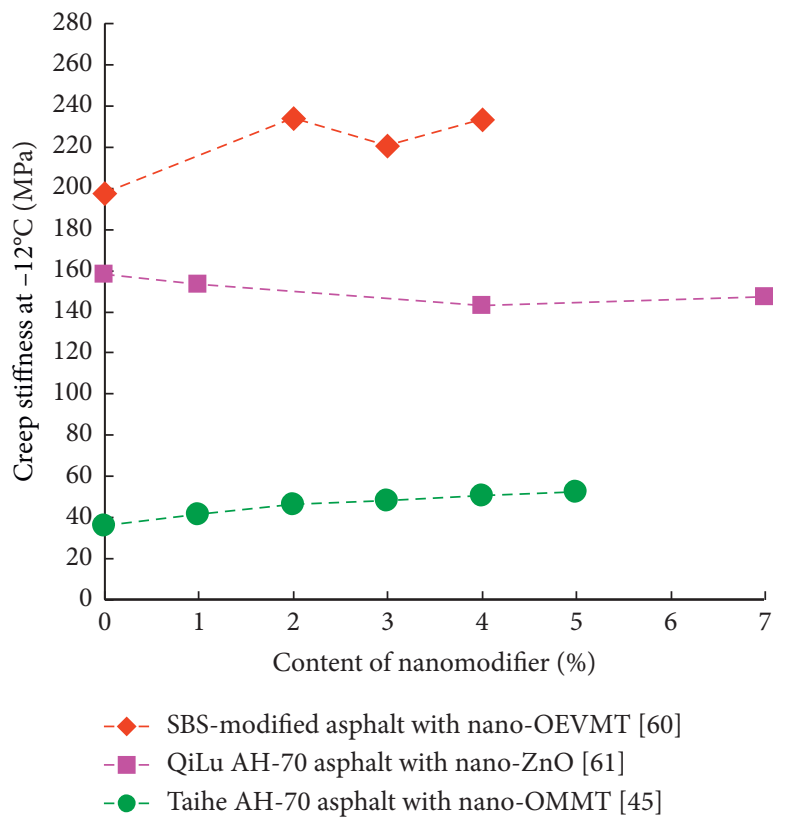

Figure 12: Creep stiffness and nanomodifier content.

nano- $\mathrm{ZnO}$-modified asphalt using the substrate method, and the mixing temperature of $170^{\circ} \mathrm{C}$ and mixing duration of 30 minutes were used at last. Zeng [81] declared that the optimum mixing temperature and time were $150^{\circ} \mathrm{C}$ and 120 minutes, respectively, based on the high- and low-temperature properties of nano-Rectorite (nano-REC) and nano- 


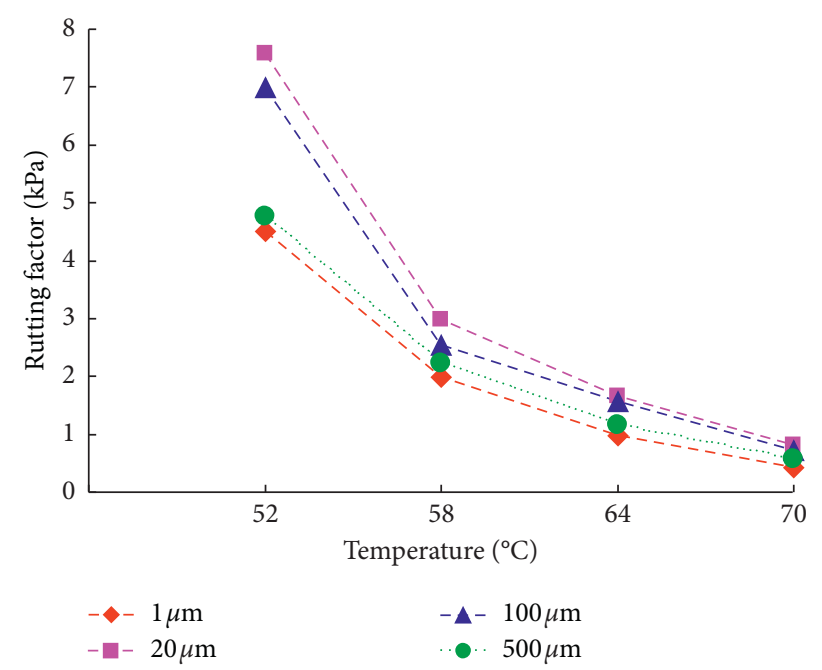

FIgURE 13: Rutting factor of different nano-SiC particle size.

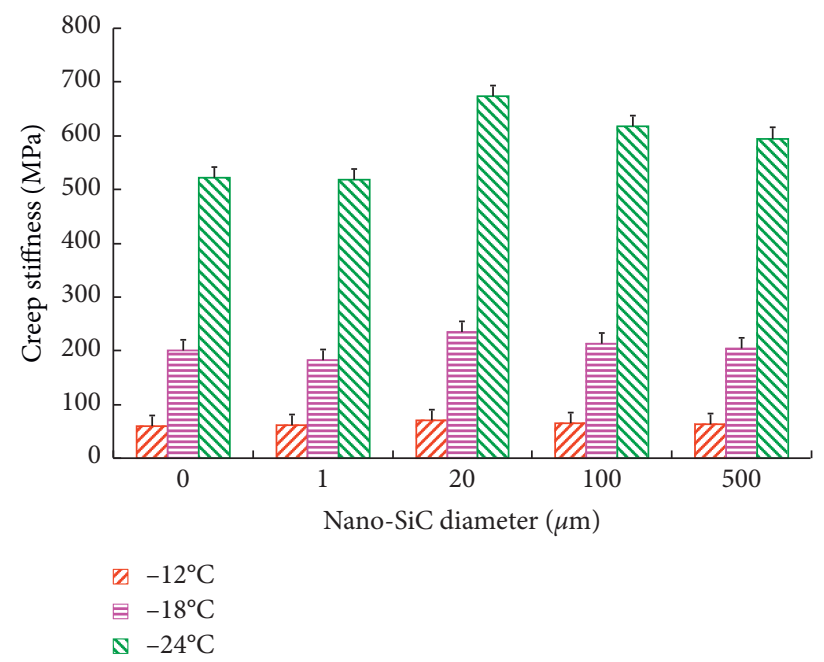

Figure 14: Creep stiffness of different nano-SiC particle size.

MMT-modified asphalt. Wang [37] investigated the mixing temperature and duration effect on the high- and lowtemperature properties of nano-MMT/SBS-modified asphalt and found that the optimum mixing temperature and time were $170^{\circ} \mathrm{C}$ and 120 minutes, respectively. For nano- $\mathrm{TiO}_{2} /$ $\mathrm{CaCO}_{3}$-modified asphalt, Wang [82] obtained the same results and reported that agglomeration of nanoparticles would still occur under the rotational speed of $4000 \mathrm{rpm}$, while its ductility at $10^{\circ} \mathrm{C}$ would reduce under the rotational speed of $7000 \mathrm{rpm}$. Moreover, the rotational speed of $5000 \mathrm{rpm} \sim 600 \mathrm{rpm}$ should be used. Wei [83] and Sun et al. [24] studied the dispersant and organic reagent effect on high- and low-temperature performance of nanomodified asphalt, respectively, and found that surface modification of nanoparticle had a very clear impact on asphalt high- and low-temperature performance. Xiao et al. [84] studied the high- and low-temperature performance of nano-ZnO SBSmodified asphalt using Zhonghai AH-70 original asphalt and three modified asphalt preparation methods and found that the high-temperature stability and low-temperature anticracking performance of asphalt could be improved by the nano-ZnO, and they were affected by modified asphalt preparation methods. Typical findings are shown in Figures $17-26$ in this regard.

Typical findings indicate that it seems that there are no consensus opinions for the preparation method of 

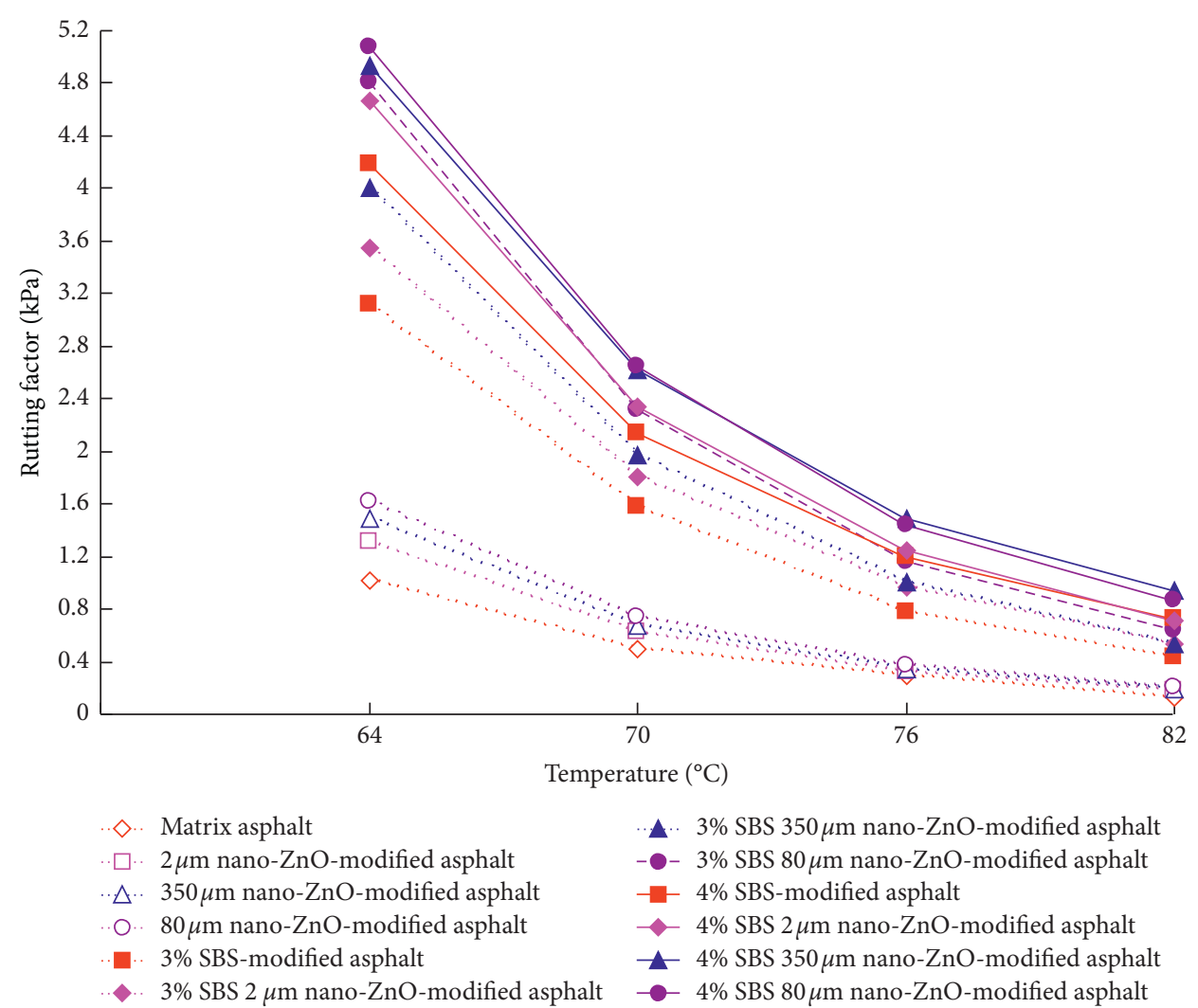

Figure 15: Nano-ZnO particle size effect on rutting factor.

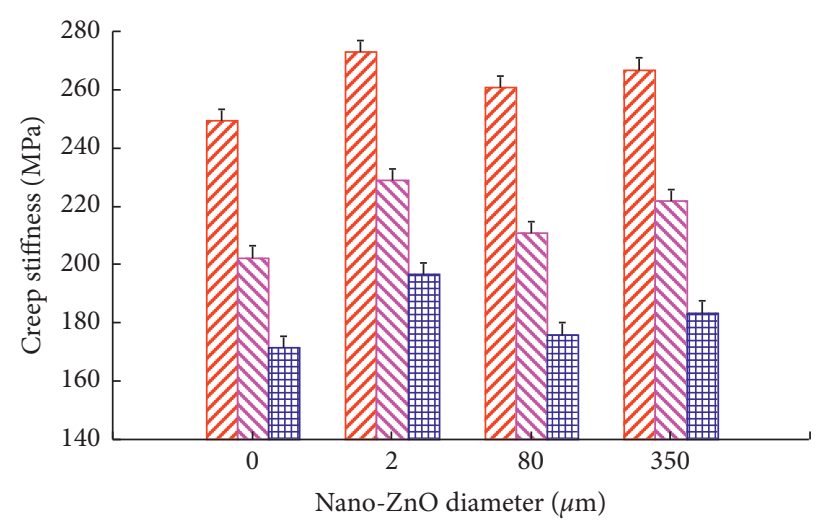

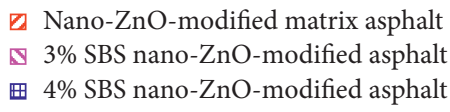

Figure 16: Nano-ZnO particle size effect on creep stiffness.

nanomodified asphalt. The preparation parameters of mixing duration, speed, and mixing temperature have a significant effect on the high- and low-temperature performance of nanomodified asphalt. Moreover, for the same original asphalt, the effect of preparation parameters on the high- and low-temperature performance of its nanomodified asphalt is different. Meanwhile, dispersant, organic reagent and preparation parameters have an important influence on 
TABLE 1: Typical preparation parameters used by various researchers.

\begin{tabular}{|c|c|c|c|}
\hline Type of nanomaterial & Mixing temperature $\left({ }^{\circ} \mathrm{C}\right)$ & Rotational speed (rpm) & Mixing duration (minutes) \\
\hline Nano-OBT [33] & 160 & 4000 & 60 \\
\hline Nano-MMT [39] & 160 & 2500 & 180 \\
\hline Nano-OMMT [43] & $175-185$ & 4000 & 45 \\
\hline Nano-CNT [51] & $150-160$ & 5000 & 60 \\
\hline Nano-OMNC [52] & $150-160$ & 4000 & 120 \\
\hline Nano-SiC [58] & 160 & 5000 & 45 \\
\hline Nano-SiO ${ }_{2}[12]$ & 130 & 4000 & 120 \\
\hline Nanosized hydrated lime [69] & 130 & 3000 & 120 \\
\hline Nano- $\mathrm{SiO}_{2}[11]$ & 160 & 1500 & 120 \\
\hline $\mathrm{Nano}_{-\mathrm{CaCO}}[\mathrm{C}[\mathrm{]}]$ & $140-150$ & 14000 & $4-5$ \\
\hline Nano-OMMT [71] & 150 & 5000 & 60 \\
\hline Nano-OMMT [72] & 180 & 4000 & 30 \\
\hline Nano-ZnO [73] & 150 & 4000 & 90 \\
\hline Nano-OMNC [74] & 180 & 1200 & 90 \\
\hline Graphite nanoplatelets [75] & 145 & 2000 & 120 \\
\hline Graphene oxide [76] & 155 & 4000 & 30 \\
\hline Clay nanocomposite [77] & $189-191$ & 4000 & 120 \\
\hline Nano-OMNC [78] & 160 & 2000 & 120 \\
\hline Nano- $-\mathrm{TiO}_{2}+\mathrm{CaCO}_{3}[79]$ & 150 & 4000 & 45 \\
\hline Nano-ZnO $[80]$ & 140 & 3500 & 60 \\
\hline
\end{tabular}

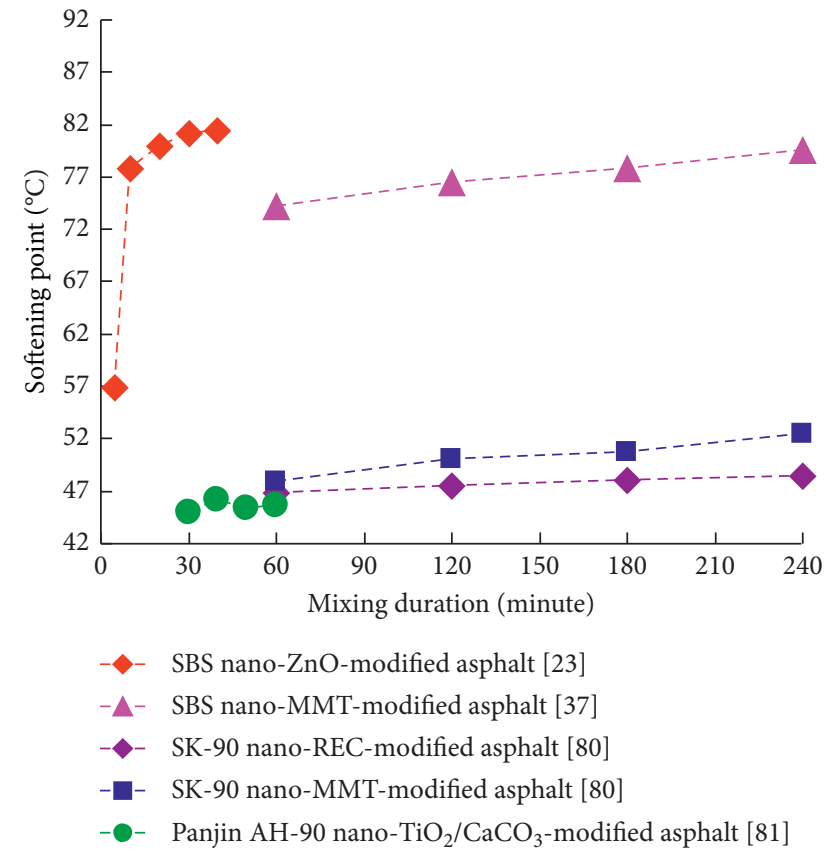

FIGURE 17: Mixing duration effect on softening point.

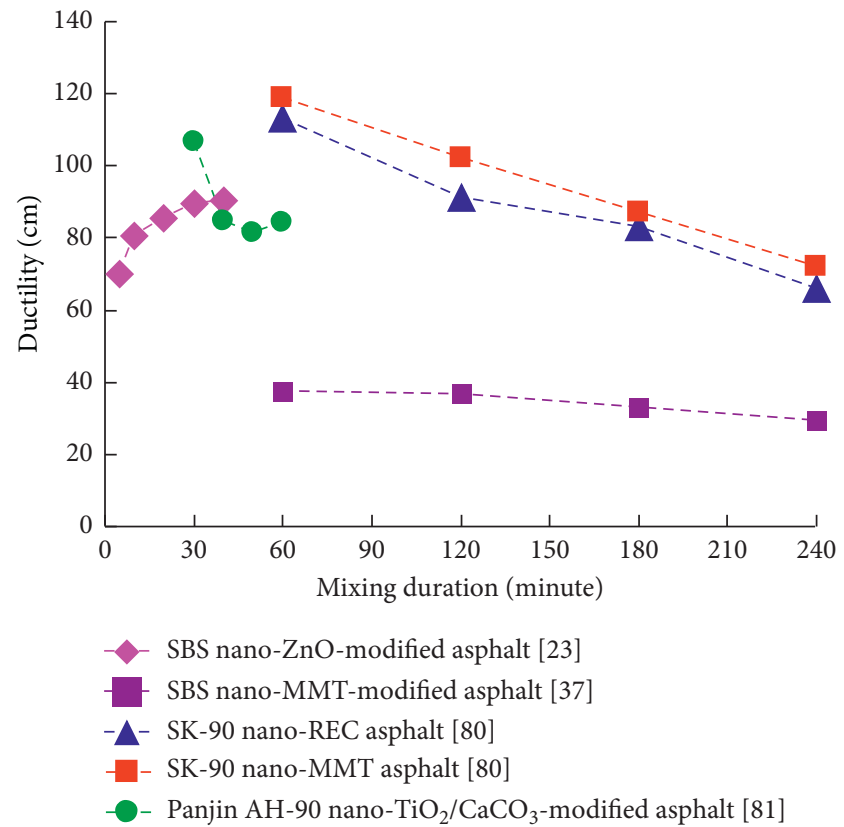

Figure 18: Mixing duration effect on ductility. 


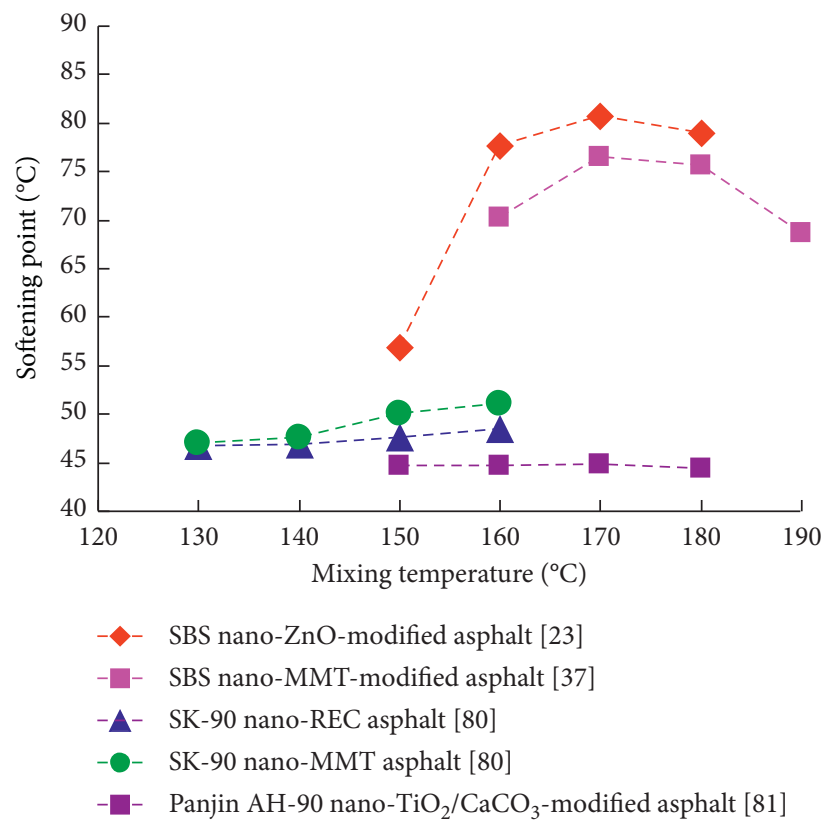

Figure 19: Mixing temperature effect on softening point.

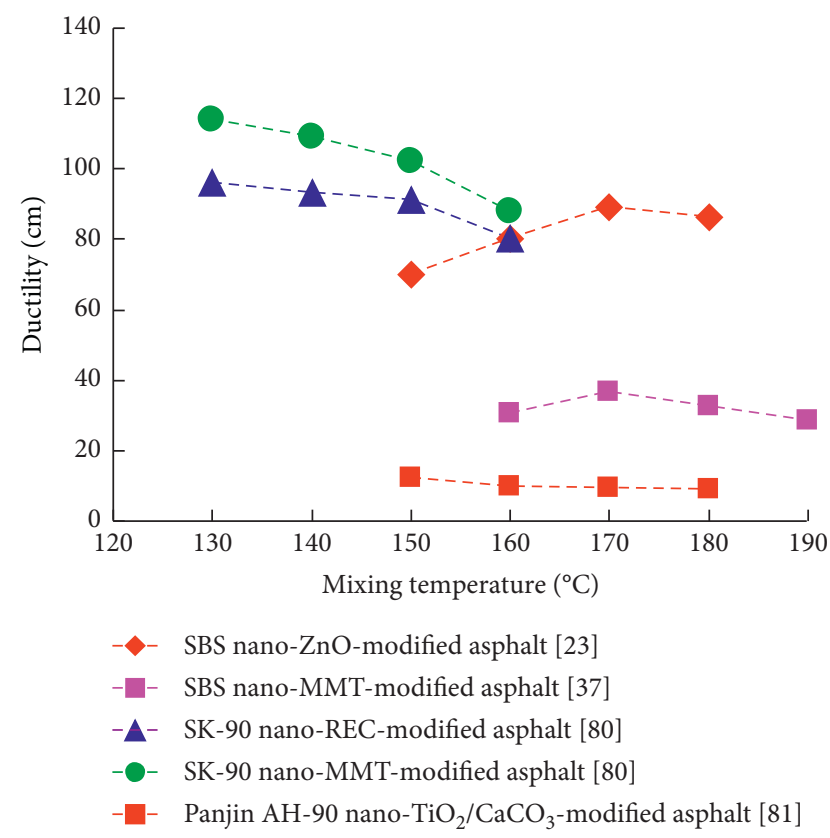

FIGURE 20: Mixing temperature effect on ductility.

the high- and low-temperature performance of nanomodified asphalt. The different microstructure, dispersion, and compatibility of asphalt binder are the possible reason

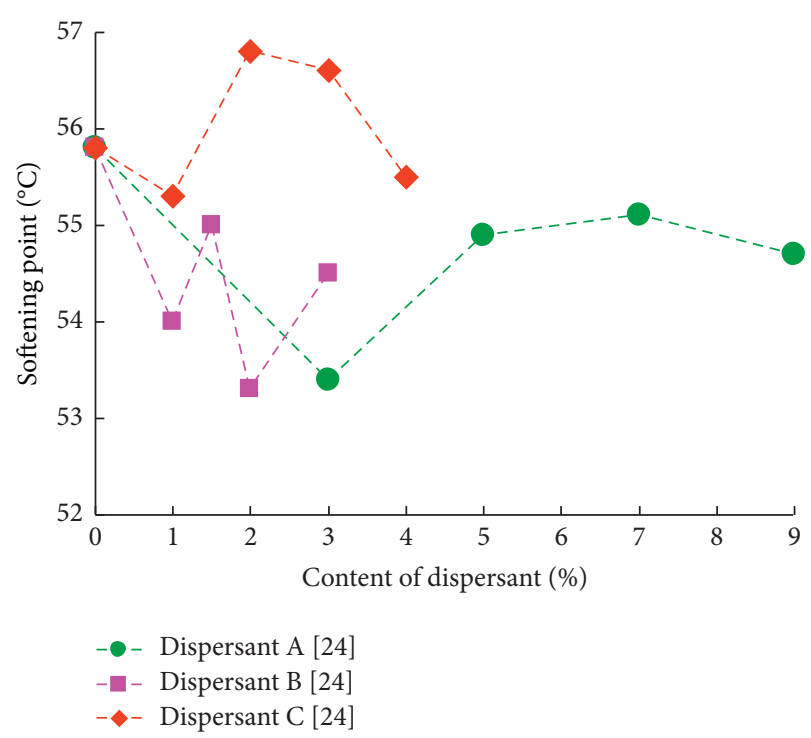

FIGURE 21: Dispersant effect on softening point.

causing the difference. So far, there is a lack of systematic investigation of the preparation effect on the high and low performance of nanomodified asphalt. Therefore, this aspect should be further studied in the future based on the micromodification mechanism. 


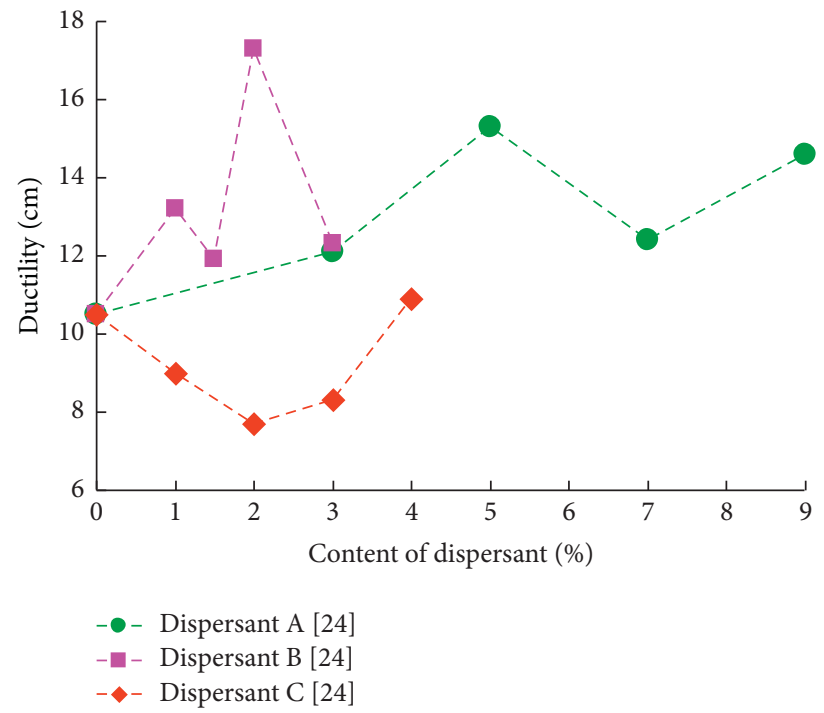

FIgURe 22: Dispersant effect on ductility.

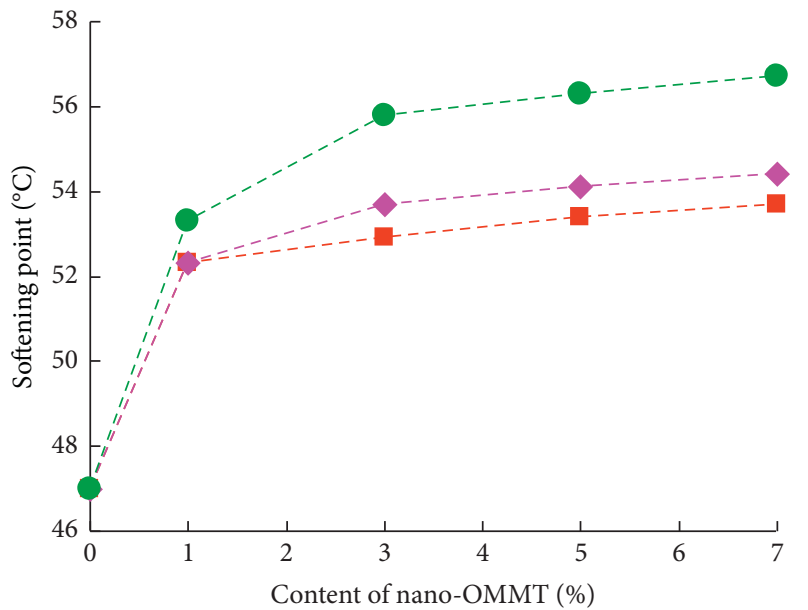

- - Organic reagent DTAC [82]

- Organic reagent 1831 [82]

- - Organic reagent 1827 [82]

FIgURE 23: Organic reagent effect on softening point.

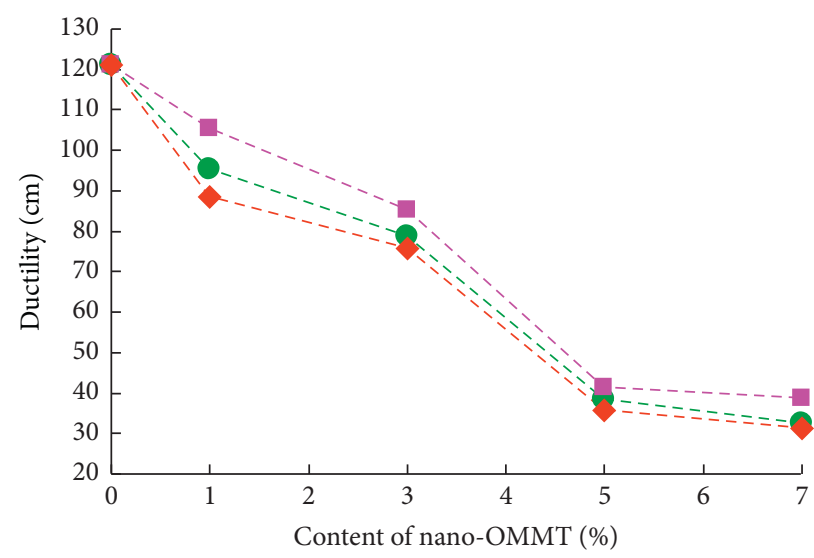

- - Organic reagent DTAC [82]

- - Organic reagent 1831 [82]

- - Organic reagent 1827 [82]

FIgURE 24: Organic reagent effect on ductility. 


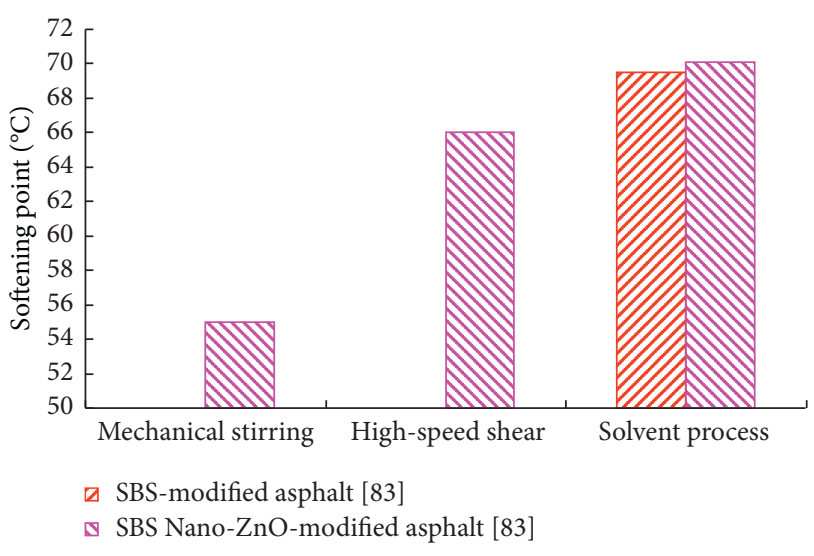

FigURE 25: Softening point of different preparation method.

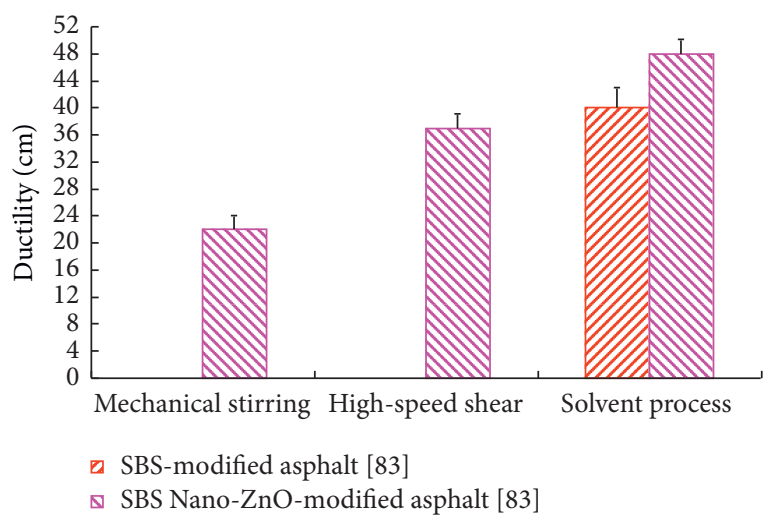

FIGURE 26: Ductility of different preparation method.

\section{Conclusions}

Nanomaterial has a high potential for application in solving the cracking and rutting failure of asphalt pavement due to its unique properties in improving the performance of asphalt. The current researches on high- and low-temperature performance of nanomodified asphalt are disjointed. This research article is a result of a comprehensive review of literature work aimed at understanding asphalt, nanomodifier, nanomodifier content, nanoparticle size, and preparation effect on high- and low-temperature performance of nanomodified asphalt, and the flowing conclusions can be drawn upon.

(1) For different original asphalt, addition of nanomodifier can increase its high-temperature properties of asphalt binder, and the increment varies with original asphalt, while its low-temperature properties of may be increased or decreased. The better the high-temperature property of original asphalt is, the stronger the high-temperature rutting resistance of its nanomodified asphalt becomes. The better the low-temperature property of original asphalt is, the stronger the low-temperature crack resistance of its nanomodified asphalt becomes. Different chemical composition of the original asphalt was the possible reason causing the difference, and its physicochemical nature seems to play a role of primary importance in the definition of the high- and low-temperature properties of final blends. Therefore, it is feasible to select the original asphalt according to its high- and low-temperature property.

(2) For different nanomodifier, its addition can increase the high-temperature properties of asphalt binder, and the rutting resistance increment depends on the type of nanomodifier, while its addition may have a negative effect on the low-temperature performance of asphalt binder. Moreover, the increase or decrease of the low-temperature cracking resistance of nanomodified asphalt depends on the type of nanomodifier too. Different chemical composition of nanomodifier and the microstructure of asphalt binder at final blends are the possible reason causing the difference. Therefore, the rational selection of nanomodifier is very important for improving the high- and low-temperature cracking resistance of nanomodified asphalt.

(3) In a certain range of nanomodifier content, with the increase of nanomodifier content, the high temperature of its nanomodified asphalt can be enhanced, while its low temperature may be reduced. The different micro structure and composition of the asphalt binder are the possible reason causing the difference. Therefore, the rational selection of nanomodifier content is very important.

(4) Nanoparticle size plays an important role in the high- and low-temperature performance of asphalt modified with nanomodifier. Based on the high- and low-temperature performance of nanomodified asphalt, the particle size of nanomodifier is not too big or too small. Preparation parameters of mixing duration, rotational speed, mixing temperature, dispersant, and organic reagent and preparation method of nanomodified asphalt have a significant effect on the high- and low-temperature performance of nanomodified asphalt.

(5) High- and low-temperature performance of asphalt directly affect the high-temperature antirutting performance and low-temperature crack resistance of asphalt pavements, and they are conflicting. Under the same conditions, any factor such as asphalt, nanomodifier, nanomodifier content, nanoparticle size, and preparation is different, the high and low temperature performance of nanomodified asphalt may be increased or decreased. Hence, the use of nanomodified asphalt for paving applications should be carefully evaluated in climates.

\section{Data Availability}

The data used to support the findings of this study are included within the article.

\section{Conflicts of Interest}

The authors declare that they have no conflicts of interest regarding the publication of this paper. 


\section{Authors' Contributions}

L. L. wrote the draft; L. Y. was responsible for methodology; Y. L. wrote, reviewed, and edited the manuscript; X. Z. was responsible for formal analysis.

\section{Acknowledgments}

This work was supported by the Hunan Provincial Natural Science Foundation of China (Grant no. 2015JJ2073) and the Hunan Provincial Department of Education of China (Grant no. 16A082). Their financial supports are gratefully acknowledged.

\section{References}

[1] C. Zhang, H. Wang, Z. You, Y. Liu, X. Yang, and J. Xiao, "Prediction on rutting decay curves for asphalt pavement based on the pavement-ME and matter element analysis," International Journal of Pavement Research and Technology, vol. 10, no. 6, pp. 466-475, 2017.

[2] V. Shan and H. Chelsea, "Flexible pavement thermal cracking performance sensitivity to fracture energy variation of asphalt mixtures," Road Materials and Pavement Design, vol. 16, 2015.

[3] W. J. Steyn, "Applications of nanotechnology in road pavement engineering," in Nanotechnology in Civil Infrastructure, K. Gopalakrishnan, B. Birgisson, P. Taylor, and N. O. AttohOkine, Eds., pp. 48-83, Springer, Berlin, Germany, 2011.

[4] F. Martinho and J. Farinha, "An overview of the use of nanoclay modified bitumen in asphalt mixtures for enhanced flexible pavement performances," Road Materials and Pavement Design, vol. 36, pp. 1-31, 2017.

[5] Z. Feng and Q. Ye, "Study on the application of new pavement materials," Green Environmental Protection Building Materials, vol. 4, pp. 1-2, 2017.

[6] J. Crucho, L. Picado-Santos, J. Neves, and S. Capitão, “A review of nanomaterials' effect on mechanical performance and aging of asphalt mixtures," Applied Sciences, vol. 9, pp. 36-57, 2019.

[7] X. Yang, A. Shen, Y. Guo, H. Wu, and H. Wang, "A review of nano layered silicate technologies applied to asphalt materials," Road Materials and Pavement Design, vol. 39, pp. 1-26, 2020.

[8] W. Liu, "Preparation and Properties of nano-layered materials/polymer compound modified asphalt," Master's dissertation, South China University of Technology, Guangzhou, China, 2015.

[9] C. Wu, L. Li, W. Wang, and Z. Gu, "Experimental characterization of viscoelastic behaviors of nano- $\mathrm{TiO}_{2} / \mathrm{CaCo}_{3}$ modified asphalt and asphalt mixture," Nanomaterials, vol. 11, no. 1, p. 106, 2021.

[10] A. Amini, H. Ziari, S. Saadatjoo, N. Hashemifar, and A. Goli, "Rutting resistance, fatigue properties and temperature susceptibility of nano clay modified asphalt rubber binder-sciencedirect," Construction and Building Materials, vol. 267, no. 1, pp. 1-11, 2021.

[11] N. I. M. Yusoff, A. A. S. Breem, H. N. M. Alattug, A. Hamim, and J. Ahmad, "The effects of moisture susceptibility and ageing conditions on nano-silica/polymer-modified asphalt mixtures," Construction and Building Materials, vol. 72, pp. 139-147, 2014.

[12] H. Yao, Z. You, L. Li et al., "Rheological properties and chemical bonding of asphalt modified with nanosilica,"
Journal of Materials in Civil Engineering, vol. 25, no. 11, pp. 1619-1630, 2013.

[13] B. Shu, S. Wu, L. Pang, and B. Javilla, "The utilization of multiple-walled carbon nanotubes in polymer modified bitumen," Materials, vol. 10, no. 4, p. 416, 2017.

[14] S. A. Ghanoon, J. Tanzadeh, and M. Mirsepahi, "Laboratory evaluation of nano-silica modification on rutting resistance of asphalt binder," Construction and Building Materials, vol. 223, no. 3, pp. 1074-1082, 2019.

[15] A. Mahmoud, V. Mostafa, R. Hamed, and H. Farshad, "Investigating effects of nano/SBR polymer on rutting performance of binder and asphalt mixture," Advances in Materials Science and Engineering, vol. 10, pp. 1-7, 2018.

[16] M. Arabani and M. Faramarzi, "Characterization of CNTs-modified HMA's mechanical properties," Construction and Building Materials, vol. 83, pp. 207-215, 2015.

[17] M. Arabani, A. K. Haghi, and V. Shakeri, "Experimental modeling the creep compliance behavior of modified asphalt mixtures with nano-zinc oxide," Journal of Polymer Research, vol. 8, no. 3, p. 131, 2014.

[18] Z. Wang, X. Guo, W. Guo, M. Chang, and W. Dai, "Viscoelasticity of hydrophobic nano-silica modified asphalt and asphalt mixture," Journal of Jilin University(Engineering and Technology Edition), vol. 50, no. 5, pp. 1709-1717, 2020.

[19] F. Bhat and M. S. Mir, "A study investigating the influence of nano $\mathrm{Al}_{2} \mathrm{O}_{3}$ on the performance of SBS modified asphalt binder," Construction and Building Materials, vol. 271, no. 2, pp. 1-12, 2021.

[20] A. Ameli, A. Pakshir, R. Babagoli, N. Norouzi, and D. Nasr, "Experimental investigation of the influence of nano $\mathrm{TiO}_{2}$ on rheological properties of binders and performance of stone matrix asphalt mixtures containing steel slag aggregate," Construction and Building Materials, vol. 265, no. 12, pp. 1-18, 2020.

[21] W. Anwar, N. Ahmad, A. Khitab et al., "Performance augmentation of asphalt binder with multi walled carbon nano tubes," Proceedings of the Institution of Civil EngineersTransport, vol. 7, pp. 1-31, 2020.

[22] K. Prabin and S. Dharamveer, "Use of nanomaterial for asphalt binder and mixtures: a comprehensive review on development, prospect, and challenges, Road Materials and Pavement Design," Road Materials and Pavement Design, vol. 38, pp. 1-46, 2019.

[23] X. Li, "Research on performance and crossblend mechanism of nanometer $\mathrm{ZnO} / \mathrm{SBS}$ modified asphalt experimental investigation of nano zinc oxide effect on creep compliance of hot mix asphalt," Master's dissertation, Yangzhou University, Yangzhou,China, 2006.

[24] L. Sun, H. Zhu, X. Xin, H. Wang, and W. Gu, "Preparation of Nano-modified asphalt and its road performance evaluation," China Journal of Highway and Transport, vol. 26, pp. 15-22, 2013.

[25] H. Zhang, Y. Gao, G. Guo, B. Zhao, and J. Yu, "Effects of ZnO particle size on properties of asphalt and asphalt mixture," Construction and Building Materials, vol. 159, pp. 578-586, 2018.

[26] C. Ye and H. Chen, "Study on road performance of nano $\mathrm{SiO}_{2}$ and nano $\mathrm{TiO}_{2}$ modified asphalt," New Building Materials, vol. 36, pp. 82-84, 2009.

[27] F. Xiao and A. Amirkhanian, "Influence of carbon nanoparticles on the rheological characteristics of short-term aged asphalt binders," Journal of Materials in Civil Engineering, vol. 23, no. 4, pp. 423-431, 2012. 
[28] H. Zhang, C. Zhu, C. Wu, and G. Xu, "Influence of multi-dimensional nanomaterials on rheological aging properties of asphalt," Journal of Building Materials, vol. 22 , pp. $238-244,2019$.

[29] L. Li, Z. Guo, L. Ran, and J. Zhang, "Study on low-temperature cracking performance of asphalt under heat and light together conditions," Materials, vol. 13, no. 7, p. 1541, 2020.

[30] S. Lee, S. Amirkhanian, N. Park, and K. Kim, "Characterization of warm mix asphalt binders containing artificially long-term aged binders," Construction and Building Materials, vol. 23, pp. 2371-2379, 2008.

[31] H.-l. Zhang, M.-m. Su, S.-f. Zhao, Y.-p. Zhang, and Z.-p. Zhang, "High and low temperature properties of nanoparticles/polymer modified asphalt," Construction and Building Materials, vol. 114, pp. 323-332, 2016.

[32] L. Tsantilis, O. Baglieri, and E. Santagata, "Low-temperature properties of bituminous nanocomposites for road applications," Construction and Building Materials, vol. 171, pp. 397-403, 2018.

[33] A. Shahabadi, A. Shokuhfar, and S. Ebrahimi, "Preparation and rheological characterization of asphalt binders reinforced with layered silicate nanoparticles," Construction and Building Materials, vol. 24, pp. 1239-1244, 2010.

[34] H. Yao, Z. You, L. Li et al., "Performance of asphalt binder blended with non-modified and polymer-modified nanoclay," Construction and Building Materials, vol. 35, pp. 159-170, 2012.

[35] H. Zhang, C. Zhu, J. Yu, C. Shi, and D. Zhang, "Influence of surface modification on physical and ultraviolet aging resistance of bitumen containing inorganic nanoparticles," Construction and Building Materials, vol. 98, pp. 735-740, 2015.

[36] S. G. Jahromi and A. Khodaii, "Effects of nanoclay on rheological properties of bitumen binder," Construction and Building Materials, vol. 23, no. 8, pp. 2894-2904, 2009.

[37] L. Wang, "Preparation and properties of montmorillonite/SBS modified bitumen composites," Master's dissertation, Wuhan University of Technology, Wuhan, China, 2007.

[38] M. Saltan, S. Terzi, and S. Karahancer, "Performance analysis of nano modified bitumen and hot mix asphalt," Construction and Building Materials, vol. 173, pp. 228-237, 2018.

[39] Z. You, J. Mills-Beale, J. M. Foley et al., "Nanoclay-modified asphalt materials: preparation and characterization," Construction and Building Materials, vol. 25, no. 2, pp. 1072-1078, 2011.

[40] J. Yu, X. Zeng, S. Wu, L. Wang, and G. Liu, "Preparation and properties of montmorillonite modified asphalts," Materials Science and Engineering: A, vol. 447, no. 1-2, pp. 233-238, 2007.

[41] S. Guo and B. Liu, "Nano material compounding effect on rheological and anti-aging properties of SBS modified asphalt," Journal of China and Foreign Highway, vol. 39, pp. 241-246, 2019.

[42] E. Iskender, "Evaluation of mechanical properties of nanoclay modified asphalt mixtures," Measurement, vol. 93, pp. 359-371, 2016.

[43] B. Golestani, F. Moghadas Nejad, and S. Sadeghpour Galooyak, "Performance evaluation of linear and nonlinear nanocomposite modified asphalts," Construction and Building Materials, vol. 35, pp. 197-203, 2012.

[44] M. E. Abdullah, K. A. Zamhari, M. R. Hainin, E. A. Oluwasola, N. A. Hassan, and N. I. M. Yusoff, "Engineering properties of asphalt binders containing nanoclay and chemical warm-mix asphalt additives," Construction and Building Materials, vol. 112, pp. 232-240, 2016.
[45] X. Tian, R. Zhang, Z. Yang, Y. Chu, Y. Xu, and Q. Zhang, "Multiscale study on the effect of nano-organic montmorillonite on the performance of rubber asphalt," Journal of Nanomaterials, vol. 2018, Article ID 9638603, 10 pages, 2018.

[46] D. Liu, H. Yao, and S. Bao, "Performance of nano-calcium carbonate and SBS compound modified asphalt," Journal of Central South University (Science and Technology), vol. 38, pp. 579-582, 2007.

[47] L. Sun, X. Xin, and P. Yu, "Pavement performance of Nano$\mathrm{SiO}_{2}$ modified asphalt mixture," Journal of Highway and Transportation Research and Development, vol. 30, pp. 1-5, 2013.

[48] H. Zhang, D. Zhang, and C. Zhu, "Properties of bitumen containing various amounts of organic montmorillonite," Journal of Materials in Civil Engineering, vol. 27, pp. 1-7, 2015.

[49] P. Han, Z. Gu, D.-M. Liu et al., "Research on properties of nano-OMMT/SBS/asphalt composites," Journal of Qingdao University, vol. 27, pp. 32-37, 2014.

[50] M. Zhang, "Nanometer zinc oxide modified asphalt and its anti-aging properties research," Master's dissertation, Chang'an University, Chang'an, China, 2015.

[51] P. Ashish and D. Singh, "High- and intermediate-temperature performance of asphalt binder containing carbon nanotube using different rheological approaches," Journal of Materials in Civil Engineering, vol. 30, p. 54, 2017.

[52] P. K. Ashish, D. Singh, and S. Bohm, "Investigation on influence of nanoclay addition on rheological performance of asphalt binder," Road Materials and Pavement Design, vol. 18, no. 5, pp. 1007-1026, 2017.

[53] C. Liu, "Study on rheological properties of OMMT/SBS modified asphalt," Master's dissertation, Dalian Maritime University, Dalian, China, 2016.

[54] Y. Fu, "Research on ageing characteristics of nano-montmorillonite modified asphalt and asphalt mixture," Doctoral dissertation, Wuhan University of Technology, Wuhan, China, 2010.

[55] G. Shafabakhsh, S. M. Mirabdolazimi, and M. Sadeghnejad, "Evaluation the effect of nano- $\mathrm{TiO}_{2}$ on the rutting and fatigue behavior of asphalt mixtures," Construction and Building Materials, vol. 54, pp. 566-571, 2014.

[56] C. Zhu, H. Zhang, G. Xu, and C. Shi, "Aging rheological characteristics of SBR modified asphalt with multi-dimensional nanomaterials," Construction and Building Materials, vol. 151, pp. 388-393, 2017.

[57] I. Amin, S. M. El-Badawy, T. Breakah, and M. H. Z. Ibrahim, "Laboratory evaluation of asphalt binder modified with carbon nanotubes for Egyptian climate," Construction and Building Materials, vol. 121, pp. 361-372, 2016.

[58] J. Sun, "Experimental study on properties of SiC nanomodified asphalt and its mixtures," Master's dissertation, Changsha University of Science andTechnology, Changsha, China, 2017.

[59] B. Du, "Preparation and properties of inorganic layered silicates modified warm mix asphalt," Master's dissertation, Hunan University, Changsha, China, 2017.

[60] Y. Chen, A. Chen, C. Li, and Z. Li, "Analysis of performance for nano-ZnO modified asphalt mixture," China Journal of Highway and Transport, vol. 30, pp. 25-32, 2017.

[61] K. Cao, W. Xu, D. Chen, and H. Feng, "High- and low-temperature properties and thermal stability of silica fume/SBS composite-modified asphalt mortar," Advances in Materials Science and Engineering, vol. 2018, Article ID 1317436, 8 pages, 2018. 
[62] K. Cao, W. Xu, D. Chen, and H. Feng, "Corrigendum to "high-and low-temperature properties and thermal stability of silica fume/SBS composite-modified asphalt mortar"” Advances in Materials Science and Engineering, vol. 2019, Article ID 9897813, 4 pages, 2019.

[63] J. Li, W. Lyu, and W. Li, "Effect of size of $\mathrm{ZnO}$ particles on asphalt properties," Road Machinery and Construction Mechanization, vol. 36, pp. 60-65, 2019.

[64] K. Alexandr, R. Dallaev, D. Burda et al., "Field emission properties of polymer graphite tips prepared by membrane electrochemical etching," Nanomaterials, vol. 10, no. 7, p. 1294, 2020.

[65] P. Kaspar, D. Sobola, K. Částková et al., "Characterization of polyvinylidene fluoride (pvdf) electrospun fibers doped by carbon flakes," Polymers, vol. 12, no. 12, p. 2766, 2020.

[66] S. Talu, Micro and Nanoscale Characterization of Three Dimensional Surfaces, Basics and Applications, Napoca Star Publishing House, Cluj-Napoca, Romania, 2015.

[67] D. Sobola, P. Kaspar, P. Tofel, and V. Holcman, "Scanning electron microscopy and energy-dispersive X-ray spectroscopy analysis of electrochemically etched graphite tips created from pencil lead," Microscopy Research and Technique, vol. 83, no. 2, pp. 196-201, 2019.

[68] P. K. Ashish and D. Singh, "Use of nanomaterial for asphalt binder and mixtures: a comprehensive review on development, prospect, and challenges," Road Materials and Pavement Design, vol. 20, pp. 1-47, 2019.

[69] A. Diab, Z. You, R. Ghabchi, and M. Zaman, "Effects of regular-sized and nanosized hydrated lime on binder rheology and surface free energy of adhesion of foamed warm mix asphalt," Journal of Materials in Civil Engineering, vol. 27, pp. 1-7, 2014.

[70] G. H. Hamedi, F. Moghadas Nejad, and K. Oveisi, "Investigating the effects of using nanomaterials on moisture damage of HMA," Road Materials and Pavement Design, vol. 16, no. 3, pp. 536-552, 2015.

[71] J.-Y. Yu, P.-C. Feng, H.-L. Zhang, and S.-P. Wu, "Effect of organo-montmorillonite on aging properties of asphalt," Construction and Building Materials, vol. 23, no. 7, pp. 2636-2640, 2009.

[72] S. S. Galooyak, B. Dabir, A. E. Nazarbeygi, and A. Moeini, "Rheological properties and storage stability of bitumen/SBS/ montmorillonite composites," Construction and Building Materials, vol. 24, no. 3, pp. 300-307, 2010.

[73] R. Li, J. Pei, and C. Sun, "Effect of nano-ZnO with modified surface on properties of bitumen," Construction and Building Materials, vol. 98, pp. 656-661, 2015.

[74] S. Zapién-Castillo, J. L. Rivera-Armenta, M. Y. Chávez-Cinco, B. Salazar-Cruz, B. A. Salazar-Cruz, and A. M. MendozaMartínez, "Physical and rheological properties of asphalt modified with SEBS/montmorillonite nanocomposite," Construction and Building Materials, vol. 106, pp. 349-356, 2016.

[75] H. Yao, Q. Dai, Z. You, M. Ye, and Y. K. Yap, "Rheological properties, low-temperature cracking resistance, and optical performance of exfoliated graphite nanoplatelets modified asphalt binder," Construction and Building Materials, vol. 113, pp. 988-996, 2016.

[76] Y. Li, S. Wu, and S. Amirkhanian, "Investigation of the graphene oxide and asphalt interaction and its effect on asphalt pavement performance," Construction and Building Materials, vol. 165, pp. 572-584, 2018.

[77] M. S. Sureshkumar, S. Filippi, G. Polacco, I. Kazatchkov, J. Stastna, and L. Zanzotto, "Internal structure and linear viscoelastic properties of EVA/asphalt nanocomposites," European Polymer Journal, vol. 46, no. 4, pp. 621-633, 2010.

[78] T. Pamplona, B. Amoni, A. Alencar et al., "Asphalt binders modified by SBS and SBS/nanoclays: effect on rheological properties," Journal of the Brazilian Chemical Society, vol. 23, pp. 639-647, 2012.

[79] Y. Cheng, H. Bi, G. Ma et al., "Pavement performance of nano materials-basalt fiber compound modified asphalt binder," Journal of Jilin University (Engineering and Technology Edition), vol. 48, pp. 460-465, 2018.

[80] Q. Zhu, "Preparation and properties analysis of asphalt modified by nano-ZnO," Applied Chemical Industry, vol. 48, pp. 1031-1034, 2019.

[81] X. Zeng, "Preparation and properties of asphalt/layered silicate nanocomposites," Master's dissertation, Wuhan University of Technology, Wuhan, China, 2007.

[82] L. Wang, "Study on the performance of nano modified asphalt pavement materials," Master's dissertation, Wuhan Jilin University, Jilin, China, 2016.

[83] L. Wei, "Preparation of organic montmorillonite being suitable for asphalt and the study on organic montmorillonite modified asphalt," Master's dissertation, Chang' an University, Chang'an, China, 2017.

[84] P. Xiao and X. Li, "Research on the performance and mechanism of nanometer ZnO SBS modified asphalt," Journal of Highway and Transportation Research and Development, vol. 24, pp. 12-16, 2007. 